\title{
Head Direction Cells Recorded in the Anterior Thalamic Nuclei of Freely Moving Rats
}

\author{
Jeffrey S. Taube \\ Department of Psychology, Dartmouth College, Hanover, New Hampshire 03755
}

Previous studies have identified neurons in the postsubiculum which discharge as a function of the animal's head direction in the horizontal plane, independent of its behavior and location in the environment. Anatomical studies have shown that the postsubiculum contains reciprocal connections with the anterior thalamic nuclei (ATN). In order to determine how the head direction (HD) cell signal is processed in the brain, single-unit recordings were monitored In the ATN of freely moving rats in order to characterize their behavioral and spatial correlates.

Animals were trained to retrieve food pellets thrown randomly into a cylindrical apparatus containing a single orientation cue. Single unit recordings in the ATN showed that approximately $60 \%$ of the recorded cells discharged in relation to the animal's head direction in the horizontal plane. Observation of the animal and quantitative analyses showed that HD cell firing was not dependent on the animal's behavior, trunk position, linear speed, angular head velocity, or location in the environment. Most of these cells were localized to the anterior dorsal thalamic nucleus. Each HD cell contained only one head direction at which the cell discharged maximally and the firing rate decreased linearly away from this preferred direction. The preferred firing directions from all cells recorded were distributed over a $360^{\circ}$ range. Quantitative analysis showed that these cells contained similar discharge parameters (peak firing rate, directional firing range) to values reported previously for postsubicular HD cells (Taube et al., 1990a). Experiments involving rotation of the orientation cue showed that the preferred firing direction could be controlled by a salient visual cue. In contrast to postsubicular HD cells, passive rotation of a restrained animal showed that most ATN HD cells ceased discharging when the animal's head was oriented in the preferred direction.

These findings demonstrate the presence of HD cells in the ATN and indicate the potential importance of this area for spatial navigation. The origin of the head direction signal is discussed and it is concluded that because of the presence of reciprocal connections between the postsubiculum and the ATN, further studies are required in order to deter-

Received Nov. 22, 1993; revised Apr. 14, 1994; accepted June 22, 1994.

I thank Will Dauphanais for construction of the behavioral apparatus, Jeffrey Dill for assistance in computer programming. David Collins for technical support in electronics, and Miguel Marin-Padilla for help with the microscopic photography. This study was supported by NIMH Grant MH48924, an award from the Hitchcock Foundation, and a Burke Award from Dartmouth College.

Correspondence should be addressed to Jeffrey S. Taube at the above address. Copyright (C) 1995 Society for Neuroscience $0270-6474 / 95 / 150070-17 \$ 05.00 / 0$ mine the direction in which this head-directional information is flowing. Finally, ATN HD cells differ from postsubicular HD cells by appearing to require volitional motoric input.

IKey words: directional orientation, spatial cognition, navigation, postsubiculum, neuronal correlates, motor efferent copyl

Much of the neural circuitry involved in processing higher order spatial information is believed to be located in the hippocampal formation, a brain area which has received extensive analysis at several different levels. Although the precise function of this brain region remains unclear, there is little doubt that it is essential for normal spatial functioning (O'Keefe and Nadel, 1978). Both animals and humans with lesions in the hippocampal region are impaired on a variety of spatial and navigational tasks (Olton et al., 1979; Morris et al., 1982; Corkin, 1984; De Leon ct al., 1984). Physiological recordings of single hippocampal neurons in awake, unrestrained animals have shown that many hippocampal neurons discharge only when the animal is located in a particular place in the environment (O'Keefe, 1976). Neurons which discharge in such a manner are referred to as place cells and the location where they discharge is termed the place field. A typical place cell discharges maximally at only one location within the environment, and its firing decreases in a linear fashion as the animal increases its distance from the center of the place field. Place fields remain stable over days and weeks as long as the environment in which the cell is recorded in remains unchanged (Thompson and Best, 1990). Place cells have been reported in the $\mathrm{CA} 1, \mathrm{CA} 3$, and dentate regions of the hippocampus (O'Keefe, 1976; Muller et al., 1987; Jung and McNaughton, 1993) and in the entorhinal cortex (Quirk et al., 1992). Further evidence supporting the hypothesis that the hippocampal formation is part of a neural network involved in spatial information come from studies demonstrating that place cell firing correlated well with an animal's ability to navigate to a goal using its spatial memory (O'Keefe and Speakman, 1987).

The hippocampus communicates with cortical areas through projections to the subicular complex, an area which is composed of three structures: subiculum, presubiculum, and parasubiculum. In contrast to the location-specific firing of hippocampal place cells, previous studies have identified neurons in the dorsal presubiculum (postsubiculum) which discharge as a function of the animal's head direction in the horizontal plane, independent of the animal's behavior and location in the environment (Ranck, 1985; Taube et al., 1990a). These cells are referred to as head direction (HD) cells because they only discharge whenever the animal points its head in a particular direction. The head direction at which the cell discharged maximaliy is referred to as 


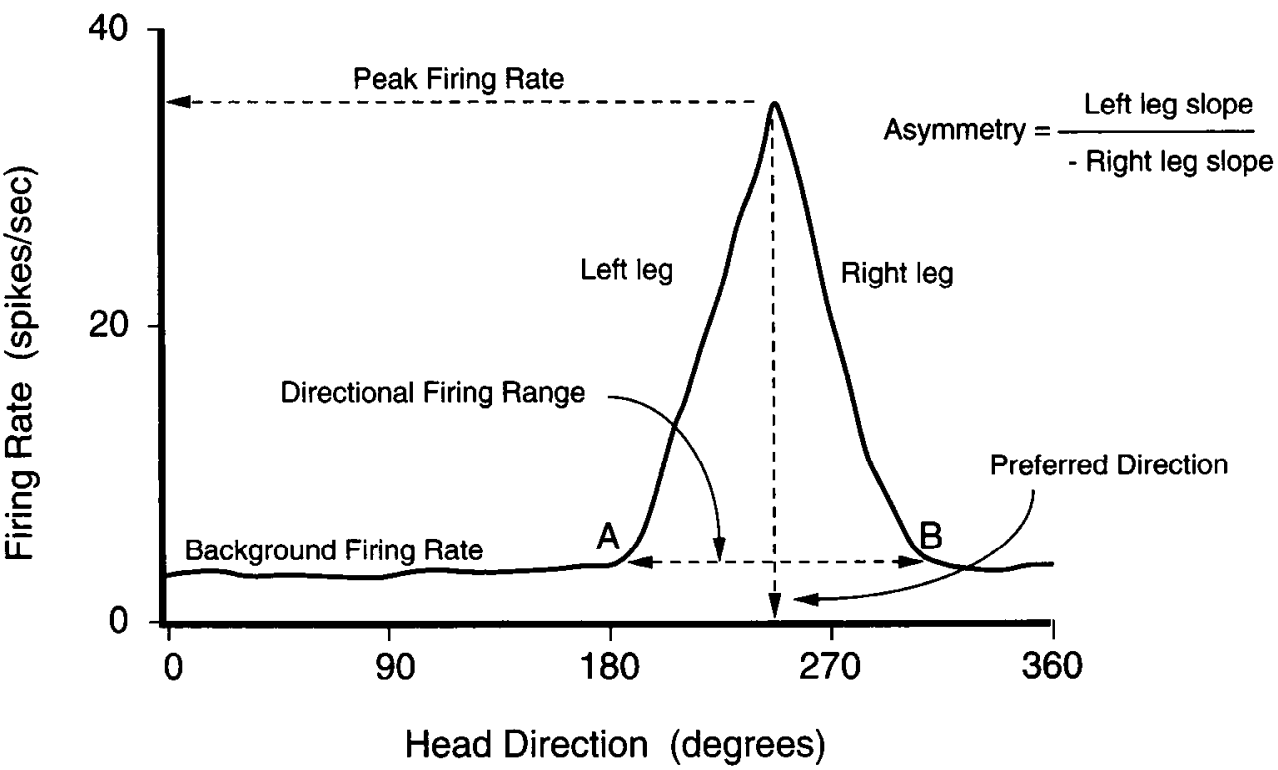

Figure 1. Illustration showing the different firing parameters for a HD cell. The solid curve shows the firing rate as a function of head direction. Using the best-fit lines for the two legs and the mean background firing rate the function is modeled as a triangle. The observed peak firing rate is the maximum firing rate of the cell whereas the triangular peak firing rate is the firing rate at the apex of the triangle. Similarly, the observed preferred direction is considered to be the preferred direction at the observed peak firing rate, whereas the triangular preferred direction is the head direction corresponding to the apex of the triangle. the preferred firing direction. A previous study showed that a HD cell's preferred direction can be controlled by an external cue (landmark) in the environment, since rotation of the cue led to a near equal shift in the preferred firing direction of the cell (Taube et al., 1990b). The HD cell signal is not a pure sensory signal, however, because HD cells continue to discharge in the absence of the cue.

Although many of the discharge properties of HD cells have been well characterized, it is unclear how this spatial signal is processed. Head direction cells were first reported in the postsubiculum (Ranck, 1985; Taube et al., 1990a), an area which receives extensive projections from the subiculum (Sorensen and Shipley, 1979), anterior thalamic nuclei (ATN) (Niimi, 1978, Thompson and Robertson, 1987a; van Groen and Wyss, 1990b), and lateral dorsal thalamic nucleus (LDN) (Thompson and Robertson, 1987a; van Groen and Wyss, 1990b, 1992). Recording studies from different hippocampal areas have never reported the presence of HD cells in CA1, CA3, or the dentate. Similarly, HD cells have not been reported in the subiculum (Barnes et al., 1990; Sharp and Green, 1994). In recording from the ATN of the rabbit, Gabriel and colleagues found that multiunit activity increased during a classically conditioned, tone discrimination paradigm (Gabriel et al., 1977; Foster et al., 1980). However, because these studies used multiple unit recording techniques, it is difficult to determine what the spatial or behavioral correlates were for single units. Furthermore, these studies monitored cell activity while the animals were semirestrained in an activity wheel, and precludes an accurate assessment of the neuronal correlates. Thus, the present study was designed to determine the spatial and behavioral correlates of neurons from the ATN in awake, freely moving animals. Cells in the ATN were monitored as an animal retrieved food pellets thrown randomly into a cylindrical chamber containing a single orientation cue. The advantage in using this task is that the animal's behavior is generally uniform throughout the apparatus over time and any neuronal correlate observed can be attributed to the spatial characteristics of the animal in the chamber. This study reports that a significant percentage of cells from the anterior dorsal portion of the ATN show head-direction-specific firing and have similar firing properties as postsubicular HD cells. A preliminary report concerning some of these findings has previously been reported (Taube, 1992).

\section{Materials and Methods}

The methods used in this study were similar to those employed by Taube et al. $(1990 \mathrm{a}, \mathrm{b})$ to record from postsubicular HD cells. Accordingly, the methods are summarized briefly below and the reader should consult the above papers for details.

Apparatus and behavioral training. Long-Evans female rats $(n=8)$ were placed on a food-restricted diet and trained to retrieve food pellets thrown randomly into a cylindrical apparatus $(76 \mathrm{~cm}$ diameter, $51 \mathrm{~cm}$ high). A black curtain ( $2.0 \mathrm{~m}$ diameter) surrounded the apparatus from floor to ceiling and four overhead lights arranged uniformly at the ceiling provided illumination. The cylinder was placed on a sheet of photographic backdrop paper that was changed before each recording session. A vertically oriented color video camera (Sony XC-711) was centered over the cylinder $2.06 \mathrm{~m}$ above the floor. A sheet of white cardboard, occupying $100^{\circ}$ of arc, was taped to the inside wall of the cylinder and provided the major visual cue for orientation. Except for the card rotation experiments described below, the "cue card" was positioned at 3 o'clock as viewed from the overhead video camera for all recording sessions.

Electrode and surgical techniques. The electrodes consisted of a bundle of ten $25 \mu \mathrm{m}$ diameter nichrome wires which were insulated except at the tips. The wires were threaded through a stainless steel cannula and attached to a modified 11 pin Augat connector, which in turn was embedded in dental acrylic and made moveable through the use of three screws; for details on electrode construction, see Kubie (1984). Once animals were trained on the food-pellet retrieval task, they were anesthetized with intraperitoneal Nembutal $(45 \mathrm{mg} / \mathrm{kg})$ and injected with $0.1 \mathrm{ml}$ of atropine sulfate $(25 \mathrm{mg} / \mathrm{ml})$ to reduce respiratory problems. Using stereotaxic techniques and bregma coordinates, the electrode array was implanted just dorsal to the ATN: AP: $1.35 \mathrm{~mm}$ posterior, ML: $1.40 \mathrm{~mm}$ right, DV: $4.0 \mathrm{~mm}$ from the cortical surface (Paxinos and Watson, 1986). All surgery was conducted under sterile conditions and animals were allowed to recover for $7 \mathrm{~d}$ before cell screening commenced.

Screening, recording procedures, and data acquisition. For unit screening, the animal was attached to a 12-wire recording cable which was connected on one end to an overhead commutator (Biela Idea Development) and to the animal's headstage on the other end. Electrical signals were passed through a field-effect transistor (FET) in a sourcefollower configuration, amplified (Grass Instruments P511), band-passed filtered (300-30,000 Hz, $3 \mathrm{~dB} /$ octave) (Peavey Electronics PME8), and sent through a dual window discriminator (Bak Electronics DDIS-1) 


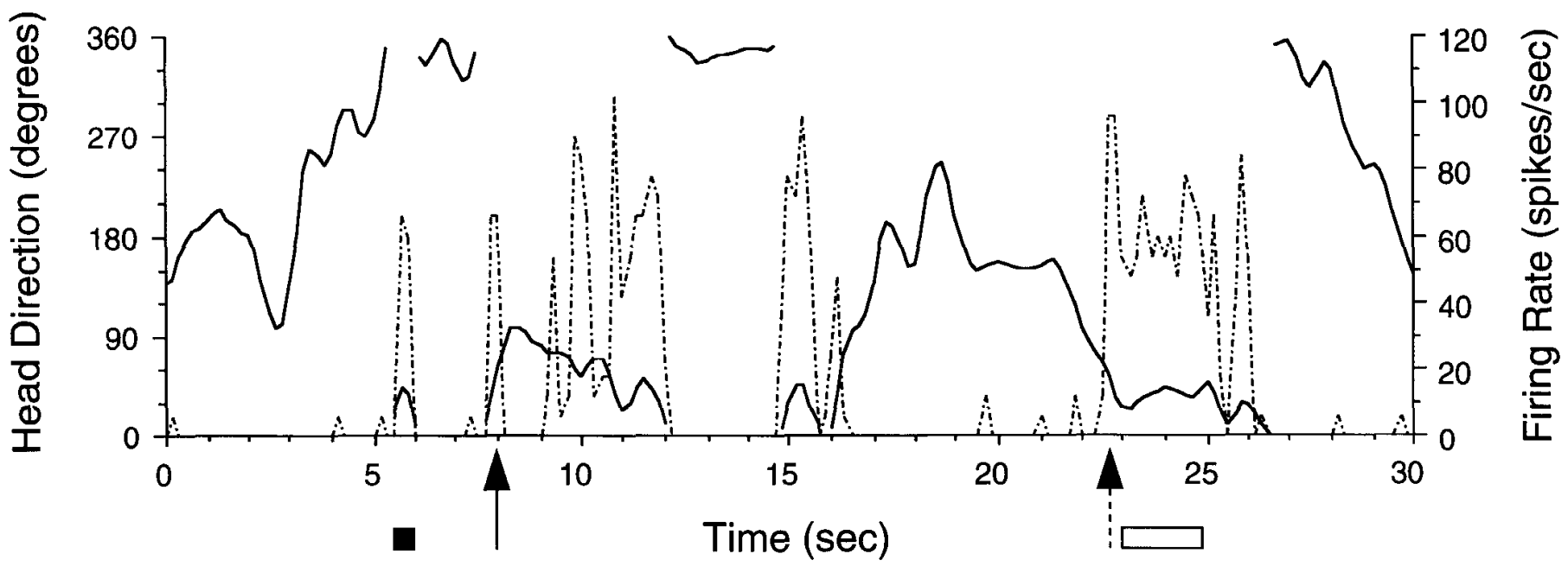

Figure 2. Graph of head direction and firing rate from an ATN HD cell. Head direction (solid line) and firing rate (dash-dot line) are plotted as a function of time for a $30 \mathrm{sec}$ period. The animal's head direction was determined every $1 / 6 \mathrm{sec}$ by averaging data from 10 consecutive samples. For the purpose of clarity, the head direction function is plotted with breaks when the animal rotated its head through the angle $0 / 360^{\circ}$. Note that the cell discharged maximally whenever the animal pointed its head in the range of head directions between $30-50^{\circ}$. The cell discharged at similar rates during periods of clockwise (dashed arrow) or counter clockwise (solid arrow) head rotations through the preferred direction. It also maintained a high firing rate when the animal turned its head rapidly (solid bar) or when it continually pointed its head in the preferred direction (open bar).

before being displayed on an oscilloscope (Tektronix 5113). Electrical activity on the 10 wires was monitored each day for several months while the electrodes were slowly advanced through the brain. When a single cell's waveform was adequately isolated from background noise, an automated video-computer tracking system (Eberle Electronics) monitored neuronal discharge while simultancously tracking the positions of two light-emitting diodes (LEDs) (one red, one green) secured to the animal's head. The red and green LEDs were spaced $10 \mathrm{~cm}$ apart along the midline of the animal's body axis and positioned over the rat's snout and back, respectively. The $x$ - and $y$-coordinates of each LED were determined to 1 part in 256 , and each rectangular subregion (pixel) of the video frame was $3.8 \times 3.8 \mathrm{~mm}$. Recording sessions were usually $8 \mathrm{~min}$ in length during which time the LEDs coordinates and spike discharge were sampled at a rate of $60 \mathrm{~Hz}$ and the data read into a computer (National Instruments DIO-32, MacIntosh IIfx). Data analysis was performed off line at a later time using a software program (LABVIEW 2.0).

Data analysis. The animal's horizontal head direction was calculated from the relative positions of the two LEDs with respect to one another and then correlated to cell firing. The animal's location in the environment was defined as the point $3 \mathrm{~cm}$ from the red LED, along the line between the two LEDs. This point corresponded to the location of the animal's head. Given the size of each pixel and the distance between the two LEDs, the maximum resolution of head direction when the animal's head axis was in the horizontal plane was calculated to be $2.17^{\circ}$. Tilting of the head backwards or forwards reduced the resolvability of head direction. For the purposes of this article, head direction analysis was performed at either 6 or $45^{\circ}$ resolution. The total time and the number of spikes discharged at each head direction for an $8 \mathrm{~min}$ session were summed from the collected samples. The cell's firing rate was determined by taking the total number of spikes in each head direction bin and dividing it by the total time spent in each head direction bin. Graphs of the cell's firing rate as a function of head direction in $6^{\circ}$ bins were then constructed. From the firing rate/head direction functions five parameters were computed which characterized the properties for each IID cell. Using the tcrminology and procedures adopted in previous work (Taube et al., 1990a), these five parameters are (1) the background firing rate and signal-to-noise ratio, (2) the preferred firing direction (the head direction associated with maximal discharge), (3) the peak firing rate (the firing rate at the preferred firing direction), (4) the directional firing range (the range of head directions in which the neuronal firing rate was greater than background level), and (5) an asymmetry ratio (the absolute value of the ratio: left leg slope to right leg slope). Each of these parameters are depicted in Figure 1.

To determine whether the cue card exerted control over HD cell firing, some cells were monitored following rotation of the cue card. After an initial $8 \mathrm{~min}$ recording session, the animal was returned to its home cage and the orientation cue card rotated either 90,180 , or $270^{\circ}$. The animal was returned to the recording room in an cnclosed box and reconnected to the recording cable. In order to disorient the animal before being reconnected, the experimenter walked around the cylinder with the box while simultaneously turning it. A second $8 \mathrm{~min}$ recording session was then conducted. After completion of this session, the animal was removed from the chamber again and the cue card returned to its original position. The animal was returned to the recording room using the same procedures for disorientation and a final $8 \mathrm{~min}$ standard session conducted.

For four animals, $10 \mathrm{HD}$ cells were monitored for $1 \mathrm{~min}$ during passive rotation of the animal. For each experiment, the animal was held firmly in the experimenter's hand with its head pointing away from the experimenter. The animal was then rotated back and forth in approximately $45^{\circ}$ arcs, with each complete sweep taking about 2-3 sec. The experimenter slowly rotated himself around the room, such that after about 20 sweeps, all $360^{\circ}$ directions had been sampled.

Histology. Electrodes were advanced 1.0-2.5 mm before terminating cell screening. At the completion of the experiment, animals were anesthetized and a small anodal current $(10-20 \mu \mathrm{A}$ for $10 \mathrm{sec})$ was passed through one of the recording wires in order to conduct a Prussian blue reaction. The animals were perfused with $10 \%$ formalin (in saline), the brains removed and placed in $10 \%$ formalin for at least $48 \mathrm{hr}$. The brains were then placed in a $10 \%$ formalin containing $2 \%$ potassium ferrocyanide for $24 \mathrm{hr}$ and then reimmersed in $10 \%$ formalin $(24 \mathrm{hr}$ ) before being placed in $20 \%$ sucrose for $24 \mathrm{hr}$. They were then sectioned $(40 \mu \mathrm{m})$, stained with cresyl violet, and examined microscopically for localization of the recording sites.

\section{Results}

\section{Cell sample}

A total of 107 cells were recorded from eight animals. Isolated units were classified either as $\mathrm{HD}$ cells or other cells. Qualita- 

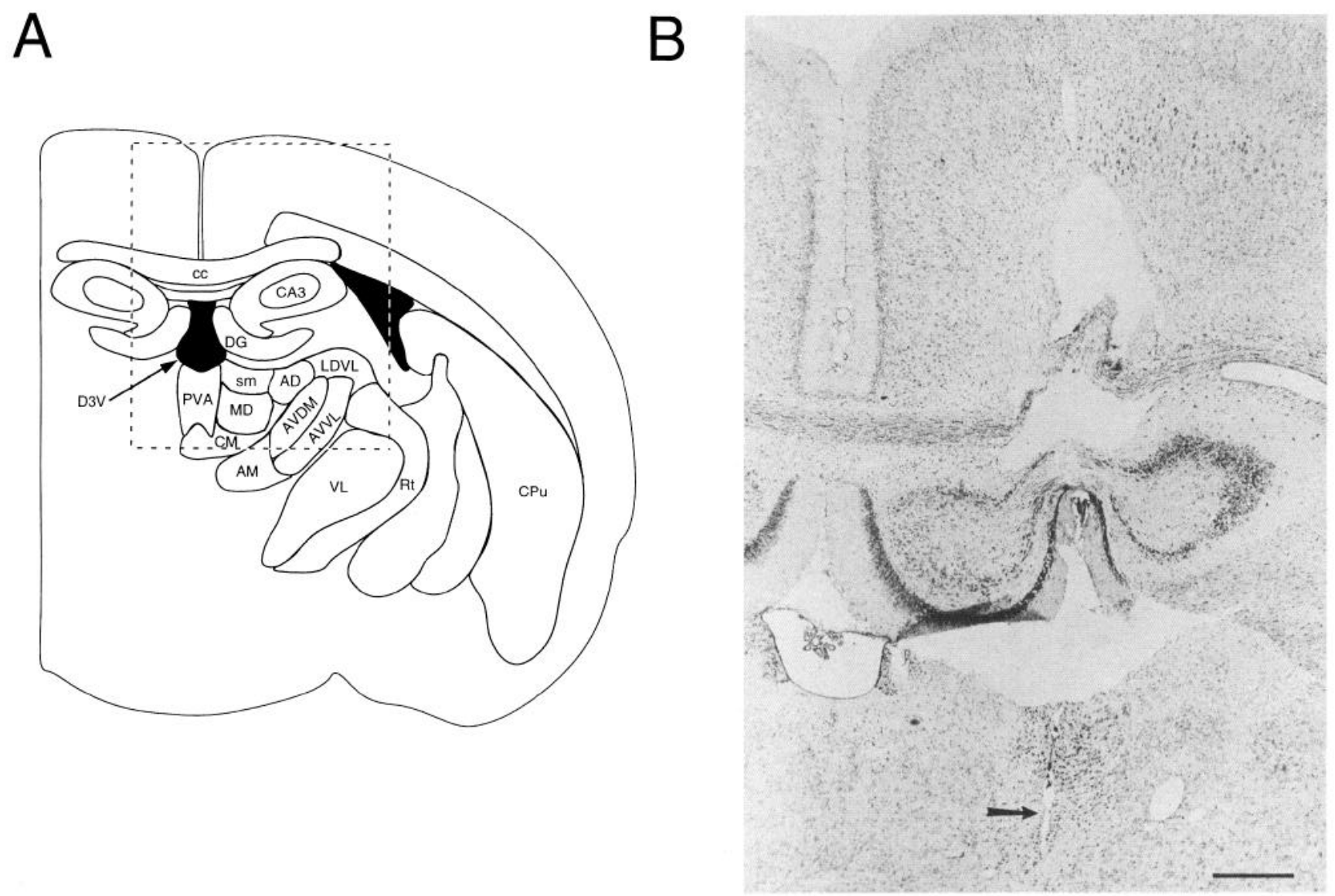

Figure 3. Photograph of recording site. A, Schematic diagram of a coronal slice around the anterior thalamic nuclei at $1.80 \mathrm{~mm}$ posterior to bregma. The dashed boxed shows the region from which the photograph in $B$ was taken. $B$, Photograph of a coronal slice stained with cresyl violet showing the electrode track (arrow) passing through the anterior dorsal thalamus. Abbreviations: $A D$, anterior dorsal thalamic nuc.; $A M$, anterior medial thalamic nuc.; $A V D M$, anterior ventral dorsal medial thalamic nuc.; $A V V L$, anterior ventral ventral lateral thalamic nuc.; $C A 3$, CA3 hippocampus; $c c$, corpus callosum; $C M$, central medial thalamic nuc.; $C P u$, caudate putamen; $D 3 V$, dorsal third ventricle; $D G$, dentate gyrus; $L D V L$, lateral dorsal ventral lateral thalamic nuc.; $M D$, medial dorsal thalamic nuc.; $P V A$, paraventricular thalamic nuc. anterior; $R t$, reticular thalamic nuc.; $s m$, stria medularis; $V L$, ventral lateral thalamic nuc. Scale bar, $0.5 \mathrm{~mm}$.

tively, the firing characteristics of ATN HD cells resembled those recorded from HD cells in the postsubiculum. They discharged maximally as a function of the animal's head direction in the horizontal plane, and were not dependent on the animal's location within the environment. For each HD cell, there was only one head direction at which the cell discharged maximally. Their discharge was not affected by the animal's speed through the environment, trunk position, or ongoing behavior as the animal could be motionless or moving around the cylinder. For example, the animal's head could be pointed in the preferred direction and the body in another and the cell would discharge consistently. Conversely, if the body was pointing in the preferred direction, but the head was not, the cell would not discharge. In addition, there was little, if any, adaptation in cell firing rate when the animal continually pointed its head in the preferred direction. Pitch or roll of the animal's head within $90^{\circ}$ of the horizontal plane also did not significantly affect cell firing. Several of these characteristics are displayed in Figure 2, which is taken from a $30 \mathrm{sec}$ episode of an $8 \mathrm{~min}$ recording session. Figure 2 shows the firing rate of the cell as a function of time. Breaks in the head direction function (solid line) are due to the animal turning its head through the $0 / 360^{\circ}$ point and are displayed in this manner for the purpose of clarity. Note that the cell only discharged when the animal's head direction was at or near the preferred direction of $36^{\circ}$. There was minimal activity at other head directions. Inspection of this graph shows that the cell discharged during both clockwise and counterclockwise head rotations through the preferred direction (e.g., compare the firing rates and head directions around $8 \mathrm{sec}$ and $22.5 \mathrm{sec}$ indicated by arrows). Note that the cell discharged at similar firing rates during periods when the animal turned its head rapidly through the preferred direction (e.g., solid bar at $6 \mathrm{sec}$ ) and when the animal maintained a constant directional heading near $36^{\circ}$ (e.g., open bar between $23-25 \mathrm{sec}$ ).

Although locomoting around the apparatus retrieving food pellets is a simple task, it involves many complex behaviors, such as sniffing, running, rearing, turning, recognition of the food pellet, the intake of the food pellet into its mouth, eating, swallowing, and grooming. A well-trained animal performs all these behaviors at different areas in the chamber. Careful observation of the animal while monitoring cell discharge showed that these behaviors had little, if any, affect on HD cell firing.

Out of 107 cells recorded, $60(56.1 \%)$ were classified as head directional. This percentage may be an underestimate because in one animal only $1 / 13$ cells was directional. When this animal is excluded from analysis then $59 / 94(62.8 \%)$ cells were directional. Because the recording techniques used multiple electrodes, it was often possible to record more than one HD cell 


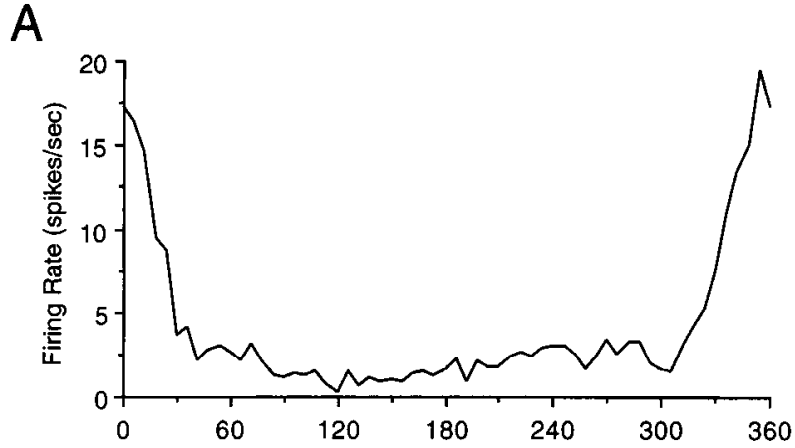

B
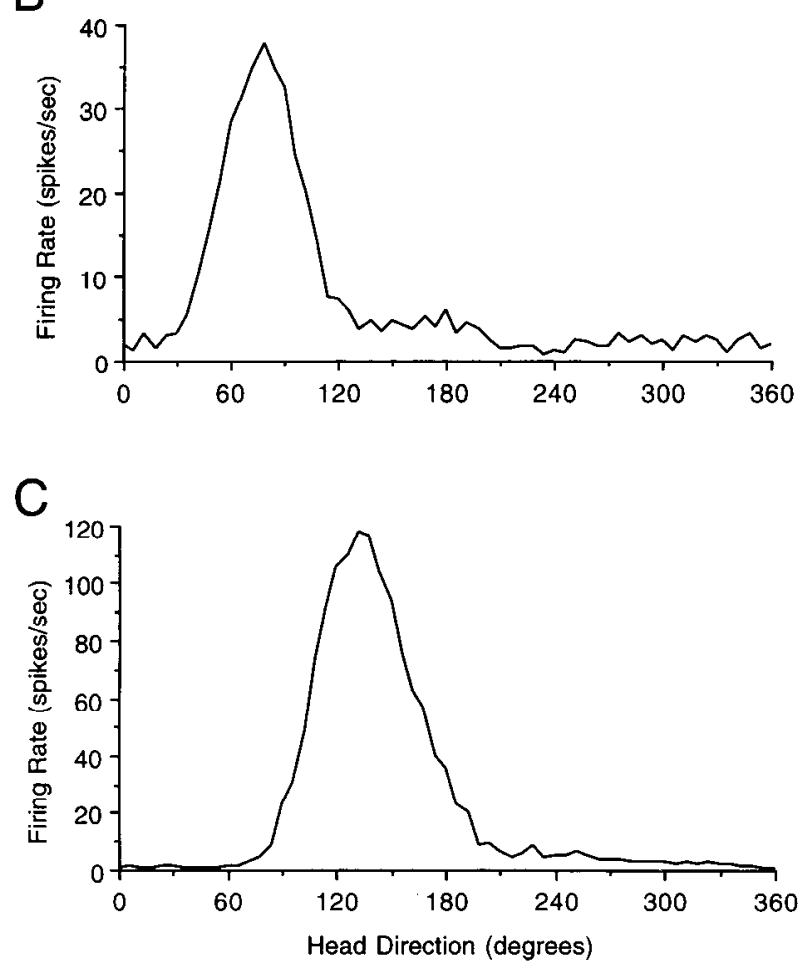

Figure 4. Firing rate as a function of head direction for three representative cells recorded in the ATN of three different animals. Each graph was obtained from an 8 min recording session and plotted using a $6^{\circ}$ bin width. Each cell has a different preferred direction. Note that the vertical axis is scaled differently in each graph. The three cells show the wide range observed in peak firing rates. $A$, Low firing rate cell; $B$, medium firing rate cell; $C$, High firing rate cell.

simultaneously. Of the 37 cells reported, 12 cells were recorded in pairs, and 12 cells were recorded in triplets.

Other cells included (1) 24 cells which discharged continuously at high firing rates $(\sim 40 \mathrm{~Hz})$ independent of the animal's behavior; (2) 16 cells which discharged at considerably lower rates, but no spatial or behavioral correlates were discernible; (3) 2 cells which showed head-directional firing at one location within the apparatus; and (4) 5 cells which were classified as theta cells (Vanderwolf, 1969; Ranck, 1973). Theta cells discharged a burst of spikes at a $5-8 \mathrm{~Hz}$ frequency when the animal was running, walking, grooming, or eating. Of the five theta cells, four of them had recording sites which were $0.5-1.0 \mathrm{~mm}$ dorsal to the first encountered HD cell and were attributed to
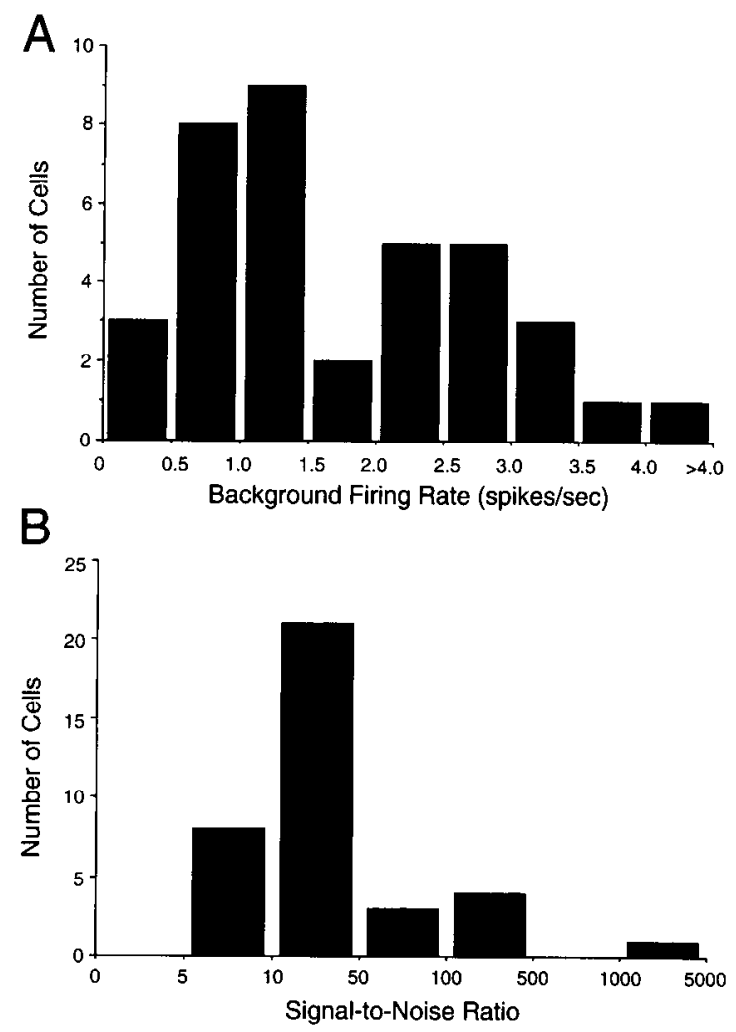

Figure 5. Histograms showing the distribution of background firing rates $(A)$ and signal-to-noise ratios $(B)$ for ATN HD cells. The signalto-noise ratio was computed using the observed peak firing rate and is plotted on a logarithmic scale.

recording sites in the hippocampus (the most anterior portion of the hippocampus is positioned just dorsal to the ATN). The paucity of theta cells in the ATN contrasts sharply to recordings in hippocampal or retro-hippocampal areas where theta cells are encountered frequently.

\section{Histology: recording sites}

The ATN has been subdivided into three areas based on cytoarchitectonics and its anatomical location. These three areas include the anterior ventral (AV), anterior dorsal (AD), and anterior medial (AM) thalamic nuclei (Paxinos and Watson, 1986). Recording tracks from all eight animals were identified passing through the ATN region. Small electrolytic lesions were made in four animals at the completion of the experiment and the bottom tip of the electrode track was identified by the Prussian blue reaction. In each of these four animals, the electrode terminated in, or passed through, the AD portion of the ATN. Because HD cclls wcrc usually recorded from more than one electrode, it was not possible to identify the recording track for each isolated cell since the lesion was made on only one electrode wire. However, observations of the other recording tracks showed that most $\mathrm{HD}$ cells were localized to the $\mathrm{AD}$ nucleus, although a few cells may have been located in the AV nucleus. Figure 3 shows a photograph from a cresyl violet stained coronal section from one animal showing the recording site. The photograph on the right is a high magnification view of the boxed area shown in the left photograph. The arrow points to the track of the electrode passing through the ATN. The Prussian blue reaction 
Table 1. Head direction cell firing properties

\begin{tabular}{|c|c|c|c|c|}
\hline \multirow[b]{2}{*}{ Parameter } & \multicolumn{2}{|c|}{$\begin{array}{l}\text { Anterior thalamic head } \\
\text { direction cells } \\
(n=37)\end{array}$} & \multicolumn{2}{|c|}{$\begin{array}{l}\text { Postsubicular head } \\
\text { direction cells } \\
(n=30)\end{array}$} \\
\hline & Mean & Range & Mean & Range \\
\hline Background firing rate & $1.99 \pm 0.35$ & $0.04-13.24$ & $1.12 \pm 0.307$ & $0.03-6.32$ \\
\hline Signal-to-noise ratio & $76.05 \pm 38.69$ & $5.11-1422.50$ & $403.7 \pm 249.3$ & $10.49-7300$ \\
\hline Observed peak firing rate & $41.08 \pm 4.40$ & $7.79-118.06$ & $34.51 \pm 5.44$ & $5.89-113.42$ \\
\hline Triangular peak firing rate & $45.14 \pm 4.83$ & $7.21-123.94$ & $35.17 \pm 5.62$ & $5.69-116.26$ \\
\hline Directional firing range & $96.24 \pm 3.25$ & $60.94-142.97$ & $89.93 \pm 3.62$ & $60.92-136.16$ \\
\hline Asymmetry ratio & $1.10 \pm 0.055$ & $0.61-2.02$ & $1.04 \pm 0.047$ & $0.67-1.67$ \\
\hline
\end{tabular}

can be observed ventral to the ATN. For this animal, the electrode was advanced approximately $800 \mu \mathrm{m}$ from the site of the last recorded HD cell. Unfortunately, the headstage detached from the other four animals before the conclusion of the experiment and an identifiable track could not be determined. In these four animals, however, the cannula track was centered over $A D$, although it was not possible to determine whether the HD cells were recorded in AD or AV.

\section{Quantitative analysis of head direction cells}

Quantitative analysis was conducted on the firing properties for 37 HD cells (eight animals) recorded from the ATN. Figure 4 shows the firing rate as a function of the animal's head direction for three representative ATN HD cells from three different animals. In general, the firing rate/head direction functions of ATN $\mathrm{HD}$ cells appeared similar to those reported for HD cells in the postsubiculum. Each cell contained a single dircction for maximal firing and no cells were encountered which contained two or more preferred firing directions. As with postsubicular HD cells, examination of the maximum firing rate from all ATN $\mathrm{HD}$ cells showed there was a wide range of peak firing rates. In addition, each cell contained about a $90^{\circ}$ range in which the firing rate was elevated above background levels. The decline of the firing rate away from the peak value appeared linear in both clockwise and counterclockwise directions. As a result, the waveform functions of the firing rate/head direction graphs were triangular in shape, with the apex of the triangle occurring in the middle of the directional firing range. For this reason, the firing rate/head direction functions were treated as triangles and values for the preferred firing direction, peak firing rate, directional firing range, background firing rate, and asymmetry ratio were determined as previously described for postsubicular HD cells (Taube et al., 1990a).
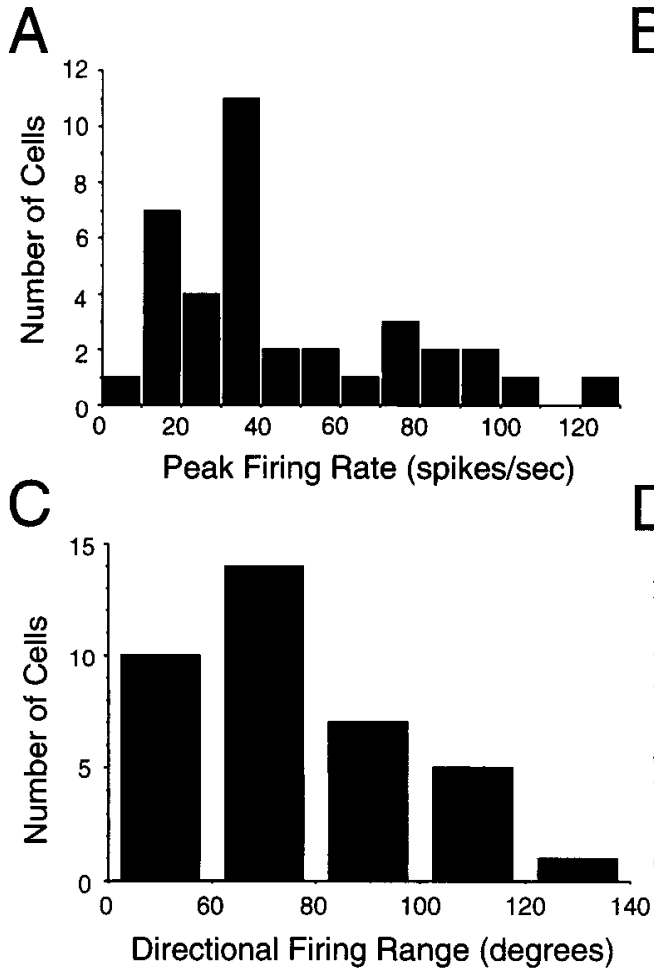

D
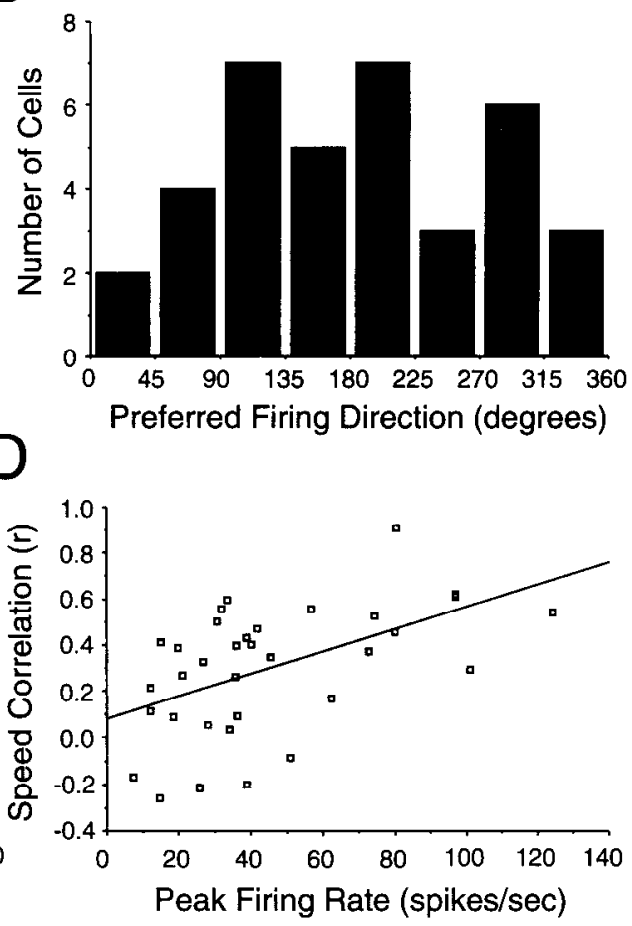

Figure 6. A, Histogram showing the distribution of ATN peak firing rates as determined using the triangular model. $B$, Histogram showing the distribution of preferred firing directions for ATN HD cells determined using the triangular model. The histogram and statistical analysis showed that preferred firing directions were distributed over a $360^{\circ}$ range, and there was no trend for preferred directions to occur at a particular head direction. $C$, Histogram showing the distribution of directional firing ranges for ATN HD cells. $D$. Scattergram of the relationship between a HD cell's peak firing rate and the speed correlation value $(r=0.515)$. The speed correlation value was determined for each cell by correlating the animal's speed with the cell's firing rate at the preferred direction. 
Figure 7. Firing rate as a function of head direction and location for two ATN HD cells recorded for $24 \mathrm{~min}$. The color-coded maps in the center show the firing rate as a function of the animal's location in the apparatus. Each colorcoded map around the center map depicts the cell's firing rate as a function of location for a particular head direction. The head direction depicted by the map is indicated by the arrow pointing to it. Each peripheral map represents a $45^{\circ}$ range of head directions centered on the arrow's direction. The colorcoded rate categories in ascending order are white, yellow, orange, red, green, blue, purple. White pixels indicate regions not visited by the animal. The large white areas where there is undersampling along the cylinder border are due to the animal's inability to point its head in a particular direction from that region of the apparatus. These series of maps show that the increased cell discharge was confined primarily to one or two maps. Within each of these maps the firing rate was homogeneous over the entire apparatus. These results indicate that the animal's location in the cylinder had little effect on ATN HD cell discharge. $A$, For the eight direction-dependent maps on the periphery, the maximum firing rate for each color category was in spikes/sec: yellow, 0.0; orange, 5.37; red, 18.95; green, 41.61; blue, 63.75 ; purple, 180.00 . For the direction-dependent map in the center, the maximum firing rate for each color category was in spikes/sec: yellow, 0.0 ; orange, 3.87 ; red, 9.43 ; green, 15.92; blue, 24.00; purple, 120.00. B, For the eight direction-dependent maps on the periphery, the maximum firing rate for each color category was in spikes/sec: yellow, 0.0 ; orange, 3.75 ; red, 8.57; green, 18.00; blue, 30.00; purple, 150.00 . For the direction-independent map in the center, the maximum firing rate for each color category was in spikes/sec: yellow, 0.0 ; orange, 3.11 ; red, 6.23 ; green, 8.82 ; blue, 12.60; purple, 60.00 .
A
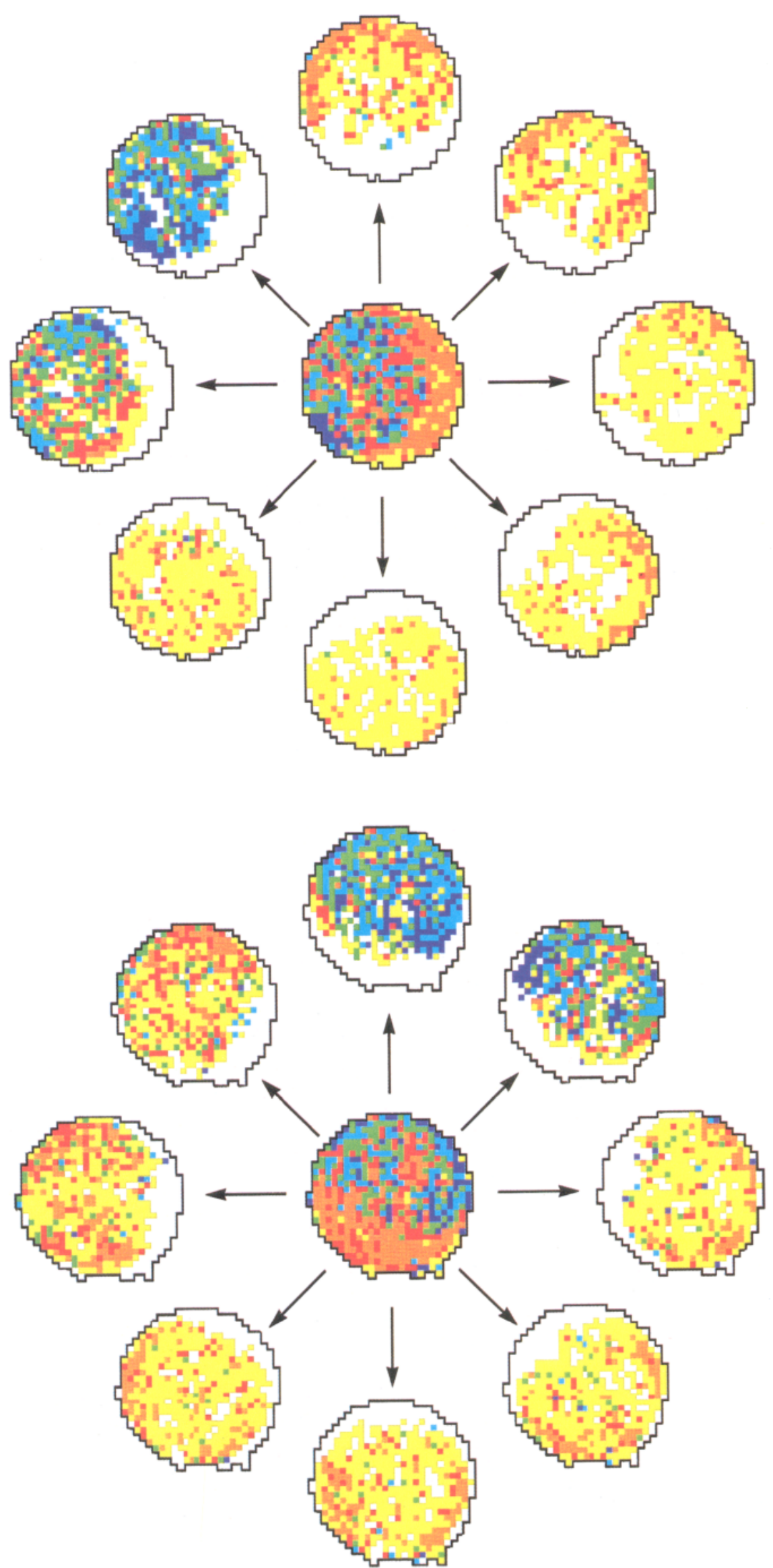

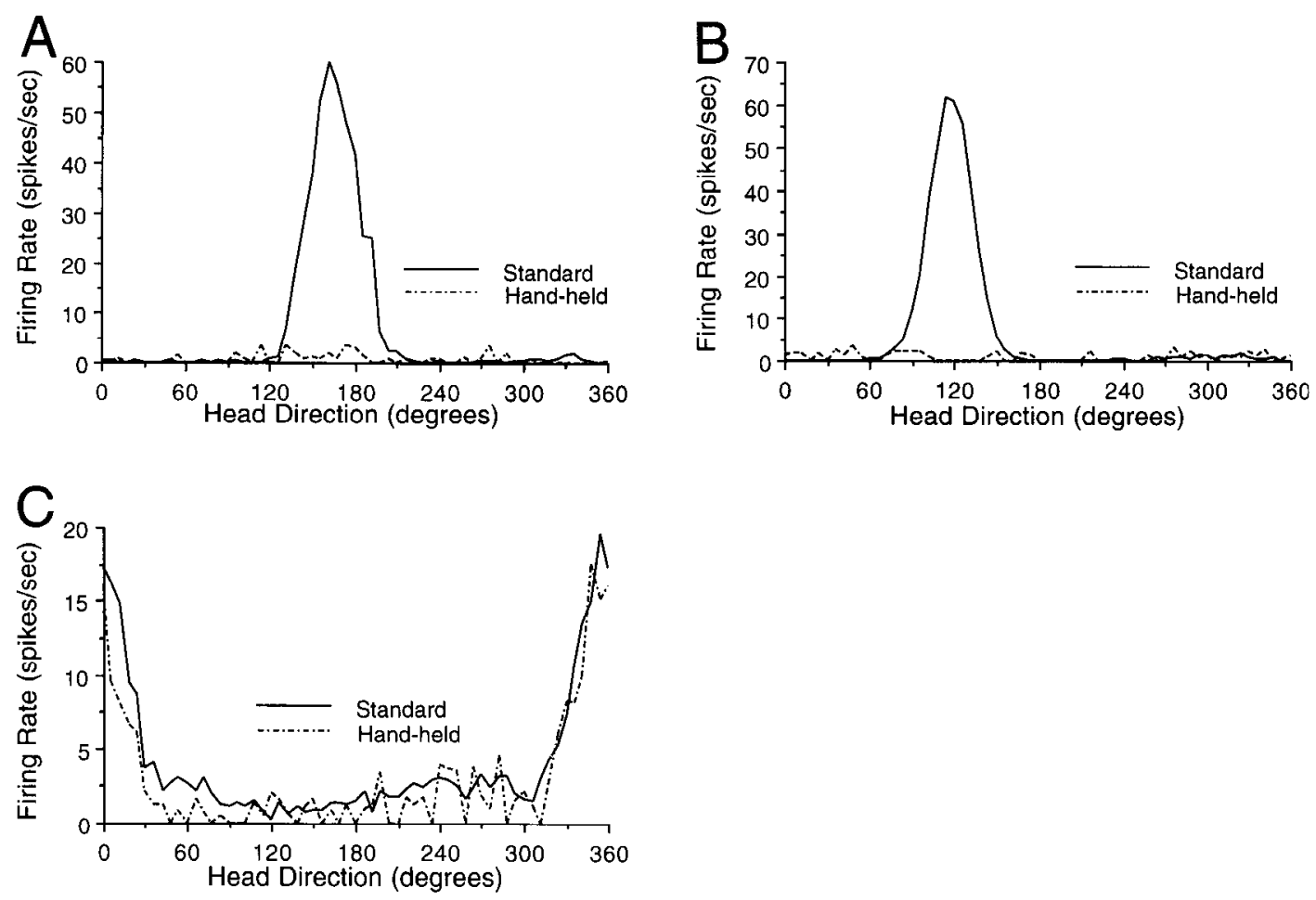

Figure 8. ATN HD cell firing following passive rotation of a hand-held animal. $A$ and $B$, Response of two HD cells recorded in separate sessions from different animals while each animal was restrained and passively rotated through $360^{\circ}$. In these two cases HD cell discharge was abolished. $\mathcal{C}$, Response of a different $\mathrm{HD}$ cell in another animal. In this case, there was no change in the cell's preferred direction, peak firing rate, or directional firing range. Solid lines indicate results from $8 \mathrm{~min}$ standard sessions when the animals were freely moving. Dash-dot lines show results from 1 min sessions when the animals were hand-held and rotated.

Background firing rates. The background firing rate for ATN HD cells was low. The mean background firing rate was 1.99 \pm 0.35 spikes/sec (range: $0.04-13.24$ spikes/sec). A signal-tonoise ratio was calculated for each cell using the observed peak firing rate. The mean signal-to-noise ratio was $76.05 \pm 38.69$ (range: $5.11-1422.50$ ). Figure 5 are histograms showing the distribution of background firing rates and signal-to-noise ratios across all cells. Some ATN HD cells discharged continuously at low rates $(\sim 1$ spike/sec) even when the animal's head was not oriented in the preferred firing direction. This firing was not attributed to artifacts or poor isolation, as the amplitude of the cell's waveform was large and well isolated from background noise.

Peak firing rates. The observed mean peak firing rate was $41.08 \pm 4.40$ spikes/sec (range: $7.79-118.06$ spikes/sec) while the mean peak firing rate using the triangular model was 45.14 \pm 4.83 spike (range: $7.21-123.94$ spikes $/ \mathrm{sec}$ ). Figure $6 \mathrm{~A}$ shows the distribution of peak firing rates computed using the triangular method. As with postsubicular HD cells, ATN HD cells with high and low peak firing rates were found within the same animal. In addition, both high and low peak firing rates were observed in well-isolated units. Statistical analysis showed there was little correlation between the observed peak firing rate and the mean level of background activity $(r=0.262)$.

Preferred firing directions. Figure $6 B$ shows the distribution of preferred directions as determined using the triangular model. Although there was a trend to find preferred firing directions pointing away from the direction of the cue card, a Raleigh test
(Batschelet, 1981) did not reject the hypothesis that this distribution was uneven $(r=0.176, n=37, p>0.275)$. The preferred direction for each $\mathrm{HD}$ cell and its location relative to other recorded HD cells within the ATN was noted in each animal. Despite careful examination no organizational pattern or systematic shift was detected for the preferred directions. Indeed, HD cells which were recorded simultaneously on the same electrode, but could be isolated based on different waveforms ( $n=$ 4) contained preferred directions which were $74,75,109$, and $174^{\circ}$ apart. This finding suggests that HD cells which were in close proximity to one another did not have similar preferred directions. Interestingly, the peak firing rate for each of these cell pairs was similar; the peak firing rates for each pair were (in spikes/sec) 7.21 and 14.79, 26.47 and $30.35,35.65$ and 41.60 , and 72.53 and 73.99 . There was little correlation between the preferred firing direction and either peak firing rate $(r=-0.143)$ or directional firing range $(r=0.062)$, which indicates that there was no trend to find particular peak firing rates or directional firing ranges associated with preferred directions pointing toward or away from the cue card.

Directional firing ranges. The mean directional firing range was $96.24 \pm 3.25^{\circ}$ (range: $60.94-142.97^{\circ}$ ). Figure $6 C$ shows the distribution of firing ranges across all $\mathrm{HD}$ cells. As with postsubicular HD cells, there was little correlation between a cell's peak firing rate and directional firing range $(r-0.175)$.

Asymmetry of the firing-rate/head direction function. The slope of the best-fit line composing each triangular leg of the firing rate/head direction function was calculated and a ratio was ob- 

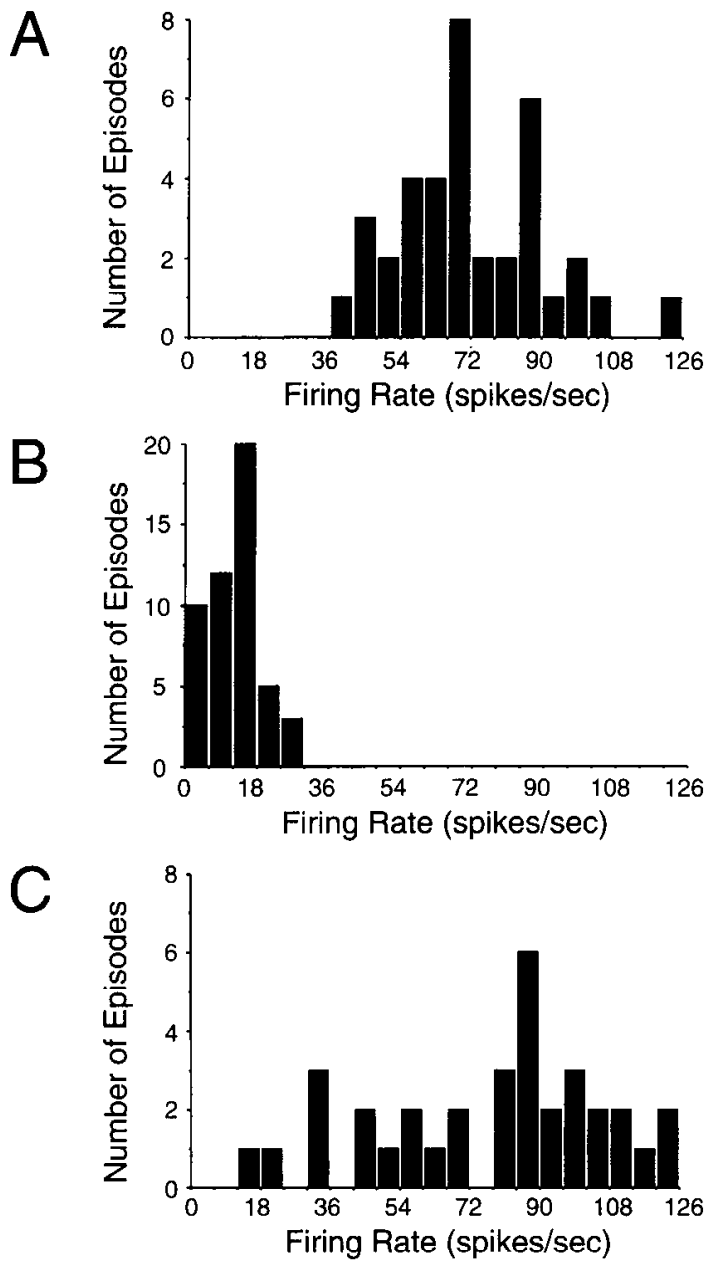

Figure 9. Histograms from three ATN head direction cells from the same animal showing the frequency of different firing rate episodes when the head continuously pointed in the preferred direction. Each episode was $1 / 6$ th sec. $A$ and $B$, Histograms for cells which discharged consistently when the head was pointed in the preferred direction. The cells in $A$ and $B$ are from a high and low peak firing rate cell, respectively. $C$, Histogram from a HD cell whose firing rate was more variable and was judged to contain an irregular firing pattern. This cell discharged at a high firing rate during some episodes (108-132 spikes/sec), but at a low rate during other periods (12-36 spikes/sec).

tained by comparing the absolute value of the left leg slope to the right leg slope. This ratio would be equal to 1.0 for a symmetrical function. The mean asymmetry ratio for ATN HD cells was $1.10 \pm 0.055$ (range: $0.61-2.02$ ) and indicates that the cell's firing rate decreased equally in both directions away from the preferred firing direction.

\section{Comparison to postsubicular $H D$ cells}

The mean values characterizing the firing rate/head direction function reported above for ATN cells were compared to values for postsubicular HD cells obtained from the previous study (see Taube et al., 1990a) and 5 additional postsubicular cells. These values are shown in Table 1. Statistical analyses ( $t$ tests) between values from the two different brain areas showed there was no significant $(p>0.05)$ difference for any parameter. In addition, a comparison was made between each of the histograms described above and similar histograms constructed for postsubicular HD cells. In each case, there was no significant difference in the relative distributions of cells for any of the discharge parameters.

\section{Firing rate as a function of the animal's head direction and location}

In general, observations of the animal while simultaneously monitoring cell discharge showed that there was an absence of location-spccific firing for ATN HD cells. Cell discharge occurred at all locations within the cylinder whenever the animal pointed its head in the preferred direction. Using color-coded maps, Figure 7 shows the discharge of two HD cells as a function of both location and head direction. Each cell was recorded for $24 \mathrm{~min}$. The procedures used to construct these maps were similar to those reported by Taube et al. (1990a) and are based on a 0.8 proportional representation of colors. In this procedure, the number of pixels representing a particular color category is 0.8 times the number of pixels in the color category of the next lowest firing rate. Each peripheral map shows the firing rate as a function of location whenever the animal pointed its head within a particular $45^{\circ}$ range. The center map shows a composite of the eight peripheral maps and represents the cell's directionindependent firing rate. The series of maps show that cell discharge occurred in only one or two of the maps, and that discharge within each map occurred over the cntire cylinder. This result indicates that ATN HD cells showed little, if any, locationspecific firing. Similar figures were constructed for 21 cells recorded for at least $16 \mathrm{~min}$ and each set of maps was examined for preferential firing in one area of the apparatus. The results for the two cells shown in Figure 7 are representative of the remaining cells, indicating that there was little, if any, variation in the firing rate across different areas within the apparatus. Thus, cell firing appeared to be primarily dependent on the animal's head direction.

\section{Hand-held sessions}

Ten ATN HD cells in four animals were monitored while the animal was held firmly in the experimenter's hands $5 \mathrm{~cm}$ above the cylinder floor and rotated back and forth slowly $(\sim 45 \% \mathrm{sec})$ in the horizontal plane. As the animal was rotated, the experimenter slowly turned around the room in order to sample all $360^{\circ}$. During the entire rotation, the animal was able to visually view the environment. Interestingly, cell discharge was nearly abolished under these conditions in $9 / 10$ cells. Firing rates for these nine cells decreased to background levels $(0-2$ spikes $/ \mathrm{sec})$ and firing rate/head direction graphs showed an absence of directional firing. These nine cells were recorded from three different animals. Figure $8, A$ and $B$, shows the results from two cells recorded from different animals for an $8 \mathrm{~min}$ standard session in the cylinder and a 1 min session when the animals were hand-held and rotated passively. The remaining cell recorded from a fourth animal did not change its discharge properties during a hand-held rotation session (Fig. $8 \mathrm{C}$ ).

\section{$H D$ cell firing versus speed of the animal and angular head velocity}

Given the volitional motor requirements, it was important to determine whether cell firing was dependent on the animal's speed or head turning velocity in the apparatus. The first issue was examined by selecting from an 8 min session all sequences of 10 consecutive samples $(1 / 6$ th $\mathrm{sec})$ when the animal maintained its head direction within a $\pm 6^{\circ}$ arc of the preferred direction. The animal's speed during each sequence was deter- 


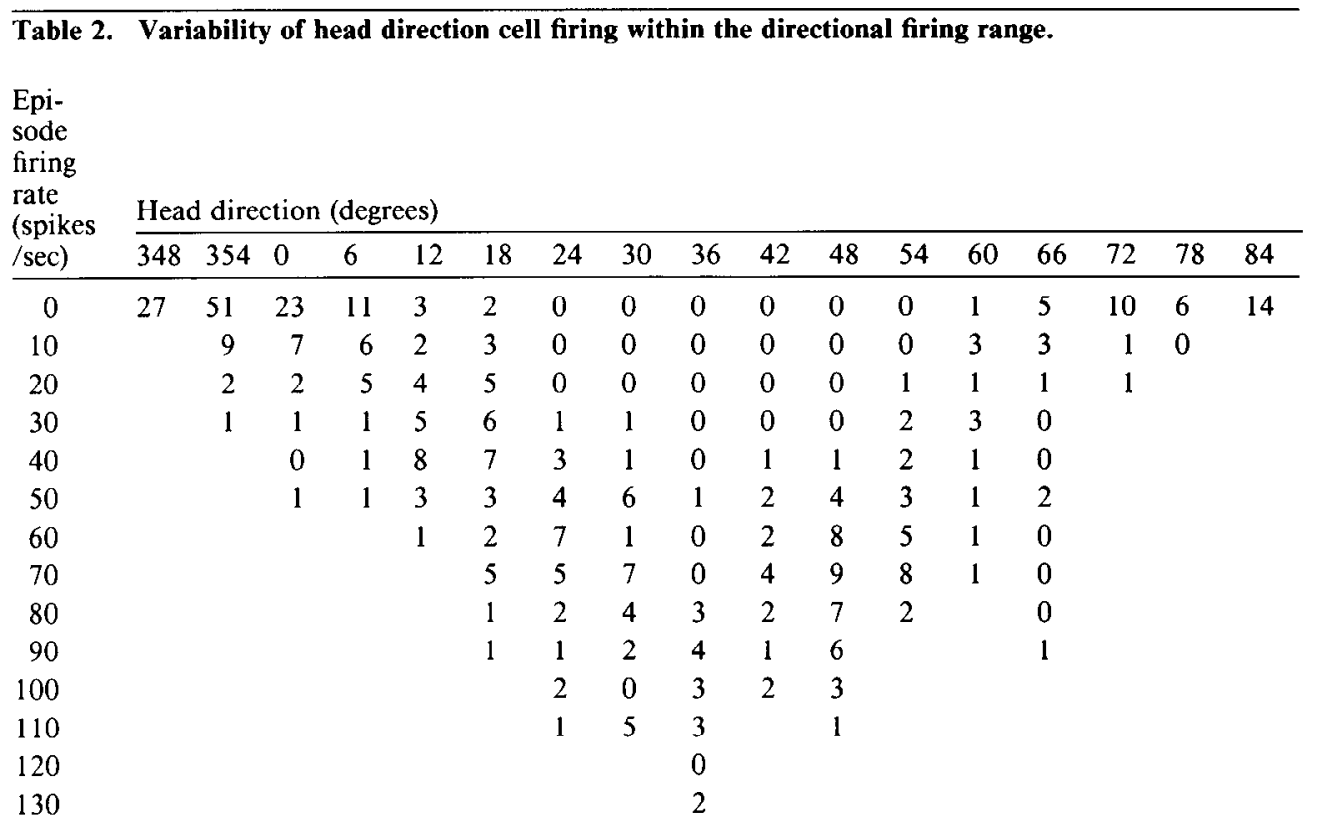

Table shows the number of episodes at a particular firing rate and head direction. Each episode consisted of six samples $\left(1 / 10\right.$ th sec). Each head direction bin represents $6^{\circ}$ of arc centered on the head direction value.

mined from the first and last sample locations of the red LED and then compared to the cell's firing rate during that sequence. A minimum of 10 episodes during an 8 min session had to occur in order for the cell to be used for analysis. Of the 37 cells, 34 cells satisfied this criteria. The mean number of episodes per cell was $24.71 \pm 1.67$ (range: 11-50). The correlation between the animal's speed and the cell's firing rate was then calculated for each cell. When the $r$ values were averaged across all cells, there was a small, but significant positive correlation between the animal's speed and the HD cell's firing rate (mean $r=0.299$ \pm 0.048 ; range: -0.257 to $0.912 ; t=6.293$, $\mathrm{df}=33, p<0.0001$ ). In addition, there was a trend for this correlation to be larger for cells with high pcak firing rates $(r=0.515)$. Figure $6 D$ is a scattergram of the speed correlation value versus the cell's peak firing rate.

In order to determine whether the rate of change in the animal's head direction correlated with cell firing, an analysis of the animal's head-turning speed and direction of turning was conducted by calculating the first derivative of the head direction/time function (referred to as the angular head velocity) and then correlating these values with the cell's firing rate. Note that the computation of this value reflects the rate of change in the animal's directional heading. However, because the orientation of the animal's body axis was not monitored (the LED tracking system only monitored head direction, not body orientation), the angular head velocity value does not distinguish between rate changes due to the head turning in relation to the body axis, or to an angular shift in the whole head/body axis relative to the environment. The difference between these two cases is that in the former situation, the directional heading changes as a result of the animal turning its head in relation to its body axis, while in the latter situation, the head remains in alignment with the body axis and the animal's directional heading changes as the entire head/body orientation shifts when the animal moves around the apparatus. Samples were selected from a session when the animal was pointing its head within a $12^{\circ}$ arc of the preferred direction. For each selected sample, the data from the two samples occurring before and after the selected sample were also obtained. These five samples composed one episode. The head direction values within this episode were then "smoothed" using a five point smoothing routine (where the head direction value at time $\left.t\left(x_{t}\right)=\left(x_{t-2}+x_{t-1}+x_{t}+x_{t+1}+x_{t+2}\right) / 5\right)$. The angular head velocity for each episode was then computed by taking the slope of the best-fit-line through these five head direction data points, and compared to the episode's firing rate. This procedure was repeated for every sample where the HD was within the $12^{\circ}$ arc centered on the preferred direction. The correlation between angular head velocity and firing rate was then determined for each HD cell by correlating the values from all episodes within a session. Positive and negative values for the angular head velocity indicate counterclockwise and clockwise turns, respectively.

The mean correlation value from all HD cells was $0.0154 \pm$ 0.0202 ( $n=37$; range: -0.157 to 0.291 ). Using zero as the expected value for the population mean, a $t$ test indicated that there was no significant trend to find cells which discharged more during clockwise or counterclockwise head turns $(t=0.761$, $\mathrm{df}=36, p>0.05)$. In order to assess whether the rate of change in the animal's directional heading correlated with cell firing, the absolute value of the angular head velocity was then correlated with cell firing. The mean correlation value from the same population of HD cells was $0.115 \pm 0.0157(n=37$; range: $-0.0988-0.424)$. Although this mean correlation value was low and indicates that the rate of change in the animal's directional heading had minimal effect on cell firing, a $t$ test showed that this mean value was unlikely to arise from a population with an expected value of zero $(t=7.332, \mathrm{df}=36, p<0.0001)$. Finally, there was no correlation between a cell's angular head velocity correlation value and the cell's peak firing rate $(r=$ $0.013)$. 

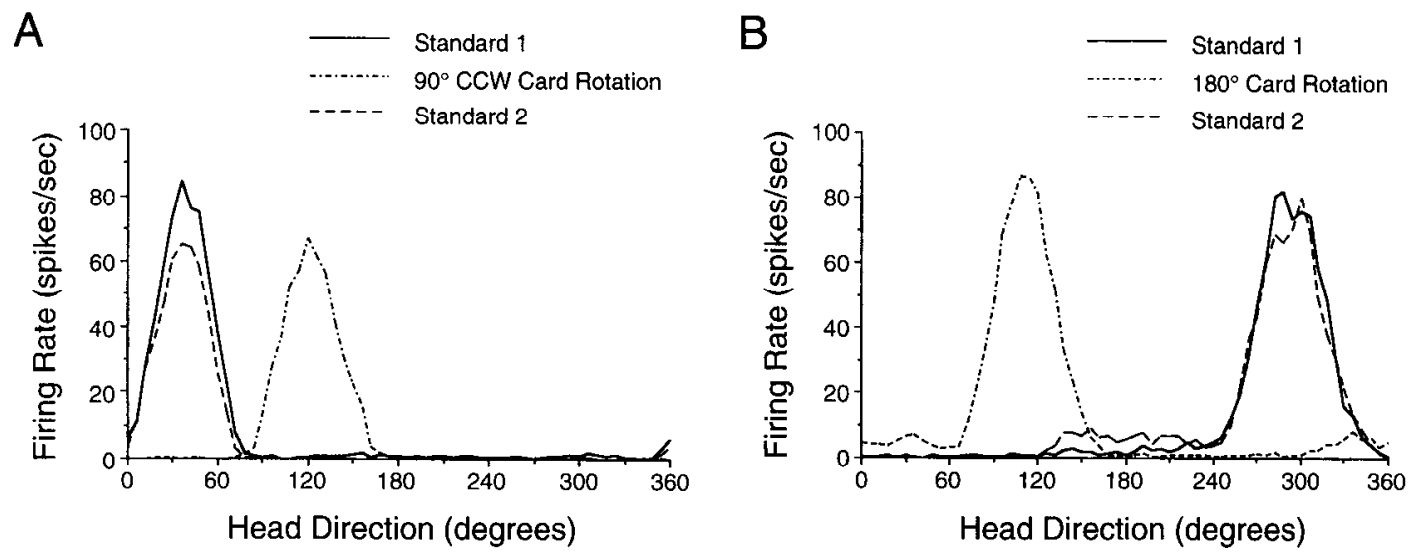

Figure 10. Head direction cell firing following cue card rotation. The animal was initially recorded in an 8 min standard session (Standard 1 , solid lines). With the animal out of view, the cue card was rotated $90^{\circ}$ counterclockwise $(A)$ or $180^{\circ}(B)$ and the floor paper changed. The animal was returned to the recording room and a second $8 \mathrm{~min}$ recording session was conducted (dash-dot lines). With the animal out of view again, the cue card was returned to its initial position. The animal was then monitored in a third 8 min session (Standard 2, dash lines). For both cells rotation of the cue card produced approximately the same shift in the preferred firing direction with little change in peak firing rate and directional firing range. In $A$, the $90^{\circ}$ counterclockwise rotation of the cue card produced an $84^{\circ}$ shift in the preferred direction. In $B$, the $180^{\circ}$ rotation of the card produced an equal $180^{\circ}$ shift in the preferred direction. The preferred direction returned to its initial value upon return of the card to its original position for both cells. The two cases shown were from different animals.

\section{Reliability and long-term stability of HD cell firing}

In order to determine the reliability of cell firing during different episodes at the preferred direction four different types of analyses were conducted. In the first analysis, histograms were constructed showing the frequency of encountering various firing rates using the 10 sample sequences obtained from the speed analysis described above. Figure $9, A$ and $B$, shows representative histograms from a low and high peak firing rate cell. The results from all the histograms showed that most cells discharged similarly each time the head direction passed through the preferred direction. This regularity in cell discharge is reflected in the unimodal character of the histograms. The histograms from all but three cells were similar to those in Figure 9, $A$ and $B$. The cells from these three exceptions contained histograms which showed a large variability in firing rates across different episodes. The cell judged to contain the most variability in its discharge is depicted in Figure $9 C$. To determine whether this variability across different episodes was attributed to variability between recording sessions, a second standard session was analyzed for these three cells. In each case the second standard session contained less variability in the range of firing rates than the first session. The three cells shown in Figure 9 were recorded from the same animal.

An important issue concerning the discharge characteristics of these cells is whether cell firing at head directions outside the range where firing rate is maximal is due to a true linear decrease in the firing rate or to statistical averaging from high and low firing rate episodes. For example, the cell shown in the Standard scssion of Figurc $10 A$ has a peak firing rate of $84 \mathrm{spikcs} / \mathrm{sec}$ and a preferred firing direction of $36^{\circ}$. However, the cell also discharged at rates of 27 and $38 \mathrm{spikes} / \mathrm{sec}$ at 12 and $60^{\circ}$, respectively. This linear decrease in the firing rate may due to an actual low firing rate at these head directions, or alternatively, they may arise from statistically averaging several episodes where the cell fired at 0 or 84 spikes $/ \mathrm{sec}$. To address this issue, the second type of analysis examined the variability in firing rate for every $1 / 10$ th sec sequence (six samples) when the animal pointed its head continuously within a $6^{\circ}$ arc. The smaller sequence period was selected in order to include a larger number of episodes, because longer sequences are excluded from analysis when the animal is rotating its head rapidly through the preferred direction. This analysis was done for every head direction (in $6^{\circ}$ multiple) within the cell's directional firing rangc. Only cells whose waveforms were judged to be well isolated from background noise were selected for this analysis. Table 2 shows the results from the cell shown in Figure $10 \mathrm{~A}$ during the Standard 1 session. Examination of this table shows that although there was variability within the firing rates for a particular head direction, the frequency of encountering firing episodes $\geq 100$ spikcs/scc only occurred within a narrow range of head directions between $24-48^{\circ}$. Furthermore, there was an absence of low firing rate episodes at these head directions. Examination of the firing rates outside this $24-48^{\circ}$ range shows that both the mean and maximal firing rates from each of these episodes was lower than the corresponding values for head directions within the $24-48^{\circ}$ range. In addition, the probability of finding firing rate episodes of zero becomes greater with increased distances away from the preferred firing direction. This pattern of results was representative for the 11 cells analyzed in this manner. In sum, this analysis shows that the cell's lower firing rates at head directions on either side of the preferred direction are "real" and are not due to statistical averaging.

In the third analysis, a comparison of the discharge characteristics was made between pairs of standard sessions recorded from the same cell. For 28 cells, a second 8 min standard session was recorded at least $10 \mathrm{~min}$ after the first session. For 14 of these cases, there was an intervening $8 \mathrm{~min}$ cue card rotation session. The mean difference in the preferred firing direction between the two standard sessions was $-0.214 \pm 1.59^{\circ}$, range: -18 to $24^{\circ}$ (the negative value represents a clockwise rotation). A $t$ test showed this difference was not statistically significant $(t=0.894, \mathrm{df}=27, p>0.05)$.

The fourth analysis determined the stability of ATN HD cells over time. Of the 37 cells, 12 cells were recorded periodically 
Table 3. Mean percentage clianges in directional firing parameters following cue card rotations

\begin{tabular}{|c|c|c|c|c|c|c|c|}
\hline $\begin{array}{l}\text { Session type } \\
\text { comparison }\end{array}$ & $n$ & $\begin{array}{l}\text { Correlation } \\
\text { coefficient } \\
(r \text { : range) }\end{array}$ & $\begin{array}{l}\text { Preferred firing } \\
\text { direction } \\
\text { (degrees) }\end{array}$ & $\begin{array}{l}\text { Peak firing } \\
\text { rate } \\
(\%)\end{array}$ & $\begin{array}{l}\text { Directional } \\
\text { firing range } \\
(\%)\end{array}$ & $\begin{array}{l}\text { Asymmetry ratio } \\
(\%)\end{array}$ & $\begin{array}{l}\text { Signal: } \\
\text { noise ratio } \\
(\%)\end{array}$ \\
\hline $\operatorname{Std} 1 / \operatorname{Std} 2$ & 14 & $0.97: 0.88-0.99$ & $4.71 \pm 1.80$ & $104.0 \pm 9.9$ & $100.4 \pm 2.5$ & $127.2 \pm 13.4$ & $120.4 \pm 28.3$ \\
\hline Std1/Rotation & 19 & $0.96: 0.87-0.99$ & $13.26 \pm 2.45^{*}$ & $90.7 \pm 5.5$ & $108.3 \pm 3.4$ & $100.4 \pm 9.4$ & $96.7 \pm 11.9$ \\
\hline
\end{tabular}

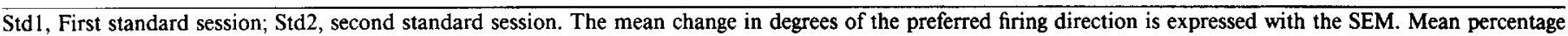
changes are expressed as percentage of control values \pm SEM from a standard session in the cylinder.

*Value reported is the directional deviation from the expected firing direction; $t=2.63, \mathrm{df}=31, p<0.02$.

over the course of several weeks. In each case the cell's firing characteristics remained stable throughout the recording period as long as the recording environment remained unchanged. Taken together, these findings indicate that cell firing remained stable across both days and different episodes when the animal pointed its head in the preferred direction.

\section{Cue card rotation}

The salient cue in the apparatus which the animal could use for orientation was the large white cue card taped to the inside wall of the cylinder. The extent to which this visual cue controlled postsubicular HD cell firing was tested by rotating the angular position of the card relative to the laboratory frame when the animal was out of view. Taube et al. (1990b) reported that rotation of the cue card led to a near equal shift in the preferred firing direction for postsubicular HD cells. In order to determine whether ATN HD cells also used this salient visual cue in a similar manner, 19 ATN cells in scven animals were monitored during a cue card rotation experiment.

Following an initial recording session with the cue card in the standard ( 3 o'clock) position, the cue card was rotated either 90,180 , or $270^{\circ}$. In each case the animal was out-of-view during the card rotation and was returned to the recording room in an opaque box. Before reconnecting the animal to the recording cable, effort was made to disorient it by randomly turning the box while simultaneously walking around the cylinder. Rotation of the cue card produced approximately the same magnitude shift in the preferred firing direction, with little change in peak firing rate and directional firing range. Figure 10 shows the recordings from two cells in two different animals when the cue card was rotated. The solid line in each figure shows the results from the first standard session, the dashed line shows the results from a rotated session, and the dash-dotted line shows the results from a sccond standard session. In Figure $10 A$, a $90^{\circ}$ clockwise rotation of the cue card produced an $86^{\circ}$ shift in the preferred direction, whereas in Figure $10 \mathrm{~B}$, a $180^{\circ}$ rotation of the card produced a $174^{\circ}$ rotation in the preferred direction. For both cells the preferred direction returned to its initial value upon return of the card to its original position (Standard 2).

Similar results for card rotation were obtained for the remaining 17 cells. Of the 19 experiments conducted, the card was rotated $90^{\circ}$ for 8 experiments, $180^{\circ}$ for 4 experiments, and $270^{\circ}$ for 7 experiments. Although the preferred firing direction shifted in near equal amounts with rotation of the cue card, there was little change in other firing properties, including peak firing rate, directional firing range, signal-to-noise ratio, or asymmetry ratio. The percentage change in each of these parameters was determined for each rotation session by comparing it to the initial standard session. A comparison in discharge properties was also conducted between the first and second standard sessions. The mean percentage change in each discharge parameter is shown in Table 3.

Although the shift in the preferred direction was usually similar to the amount of rotation of the cue card, these values were often not exactly equal. The deviation in the amount the preferred direction shifted compared to the amount expected from card rotation was determined for each rotation session by using a cross-correlation method. The firing-rate/head direction function for the experimental session was shifted in $6^{\circ}$ steps and cross-correlated with the function from the initial standard session. The amount the function needed to be shifted to yield the maximal cross-correlation was defined as the rotation of the preferred direction. Similar values were also determined between the first and second standard sessions. In theory, if HD cell firing remains stable, then the deviation between the first and second standard sessions should be zero. In general, the maximal correlation between the two functions tested was usually greater than 0.90 and indicates the strong similarity of shapes between the two functions.

The mean absolute deviation from the expected shift for the rotation sessions was $13.26 \pm 2.45^{\circ}$ (range: $0-36^{\circ}$ ). The distribution of the deviations showed there was a trend to find underrotations rather than over rotations. Of the 15 sessions where the cue card was rotated 90 or $270^{\circ}, 10$ showed underrotations, 2 rotated perfectly, and 3 showed overrotations. When the cue card was returned to its initial position and a second standard session recorded, the preferred firing direction returned to near its original value. The mean absolute deviation between the first and second standard sessions was $4.71 \pm 1.80^{\circ}$ (range $0-18^{\circ}$ ). There was no trend for this deviation to under- or overrotate; there were five deviations clockwise, five deviations counterclockwise, and four cells remained unchanged between the two sessions. A $t$ test showed that the mean deviation between the two standard sessions was significantly smaller than between the first standard session and the rotation session $(t=2.627, \mathrm{df}$ $=31, p<0.05$ ), and suggests that there are other cues, visual or nonvisual, which exert control over ATN HD cell firing.

Taken together, the results of the cue card rotation experiments are similar to those reported for postsubicular HD cells and indicate that the cue card exerts stimulus control over the angular position of the preferred firing dircction.

\section{Discussion}

The results show that a significant number of neurons in the ATN discharge as a function of the animal's horizontal head direction, independent of its behavior and location. Most of these HD cells were identified in the anterior dorsal portion of the ATN. Qualitatively, their discharge properties were indistinguishable from postsubicular HD cells. All ATN HD cells 
contained a single direction in which cell firing was maximal and pointing of the head away from this preferred firing direction lead to a cessation of cell firing. In addition, the angular position of the preferred firing direction could be controlled by a single salient visual cue in the environment, as cue card rotation led to a near-equal shift in the preferred direction of the cell. The control that the visual environment exerts over selection of a reference frame has also been found for hippocampal and entorhinal place cells (O'Keefe and Conway, 1978; Muller and Kubie, 1987; Quirk et al., 1992).

Although the results clearly show that the primary behavioral correlate of these cells is the animal's head direction in the horizontal plane, an important issue is the extent to which other behaviors may modulate cell discharge and act as a secondary correlate. Except for the manipulations wherc the animal was restrained, the quantitative analyses and observations of the animals in the chamber did not elucidate any apparent behaviors which consistently modulated HD cell firing. Because a welltrained animal samples most places from different directional headings during an 8 min session, the animal's behavior can be considered relatively uniform over both time and place within the apparatus. Thus, it is unlikely that behaviors such as eating, sniffing, grooming, and rearing contributed significantly to modulation of cell firing. Although these other behaviors were not systematically analyzed in the quantitative analysis, observations of the animal during the food pellet retrieval task showed that these behaviors had minimal effect on cell discharge. Furthermore, the notion that other on-going behaviors are playing a significant role in modulating cell firing is difficult to reconcile with the findings that (1) there was a remarkable consistency in cell firing between standard sessions, even across days, both in terms of the preferred direction and in the firing rates and firing ranges of the cells, and (2) rotation of the prominent orienting cue led to a similar shift in the cell's preferred direction. If some ongoing behavior was playing a significant role in the cell's firing, then that behavior would similarly have to shift with rotation of the cue card.

There are limitations on the conclusions one can draw concerning a cell's behavioral correlates from the food pellet retrieval task. For example, it is difficult to assess how other behaviors, or even the learning of a spatial task, might modulate HD cell firing. Although the episode analysis (Fig. 9, Table 2) showed there was a striking consistency in the cell's firing, there was some variability present across different sequences when the animal continually pointed its head in the preferred direction. The extent to which this variability can be accounted for by (1) random variability inherent in the measurements of the recording/video tracking system or (2) reflects an actual modulation of the cell's firing by the animal's ongoing behavior is unclear. Experiments which record from HD cells in tasks which keep spatial variables constant, but vary other behavioral parameters are therefore warranted to address this issue. Although, the finding that volitional movement of the animal was required to generate cell firing shows the importance of movement properties, several aspects of the animal's movements were analyzed and did not correlate well with cell discharge. For example, the correlations between either the animal's speed and firing rate $(0.299)$, or angular head velocity and cell firing rate $(0.013)$ were low. Furthermore, cell discharge continued even when the animal was motionless and pointed its head in the preferred direction. Finally, the animal's location within the chamber also did not have a strong impact on cell firing.
Several previous studies by Gabriel and colleagues recorded multiunit activity from the AV thalamus in rabbits performing a discriminative avoidance conditioning paradigm (Gabriel, 1977, 1987; Foster et al., 1980; Sparenborg and Gabriel, 1990). In this task the animals learned to initiate locomotion in an activity wheel in response to the onset of a specific frequency tone (CS+) in order to a void an electric shock (US). In addition, they had to learn to ignore a tone of a different frequency (CS-). The authors reported that AV cellular activity increased in response to the $\mathrm{CS}+$ and decreased in response to the CS- when the animals reached criterion levels of performance. Based on these studies, Gabriel has suggested that the AV thalamus, along with the medial dorsal and other midline thalamic nuclei, plays a central role in discriminating significant and insignificant sensory stimuli. Furthermore, they suggest that the activity in these thalamic nuclei represents a neural code for differentiating associatively between the different stimuli.

In contrast to the studies by Gabriel and colleagues, the findings reported here differ markedly from their studies in several ways. First, HD cells were localized to the anterior dorsal portion of the ATN, whereas most of Gabriel's recordings were from the AV area of the ATN. Second, the present study utilized single-unit recording techniques as opposed to multiunit activity. The use of multiple unit recordings would have masked the observance of HD cell activity when an animal was pointing its head in a cell's preferred direction. Third, the animals in the present study were allowed to move about their environment freely compared to being confined to a small cage in the conditioned avoidance paradigm, where the behavioral requirements may have restricted an adequate sampling of different dircctions. Fourth, therc was a species difference between the two studies; the present one used rats whereas the Gabriel studies used rabbits. Fifth, the animals performed different tasks in the two studies. Sixth, its possible that the population of cells which were not correlated with the animal's head direction in the present study (approximately $40 \%$ of the recorded cells) might be responsive to aspects of learning an avoidance conditioning paradigm as in the Gabriel studies.

The findings reported here and by Gabriel and colleagues have implications regarding the functional role of the ATN. Whereas these investigators suggest that the ATN is involved in learning discriminations between different types of sensory information, the finding that a significant number of ATN cells contain head direction correlates suggests that the ATN is serving a more global role in directing behavior. The presence of HD cells in the ATN is consistent with both anatomical and behavioral findings. The ATN contains reciprocal connections with the postsubiculum and it was in the postsubiculum where HD cells were first identified (Ranck, 1985; Taube et al., 1990a; van Groen and Wyss, 1990b). Sutherland and Rodriguez (1989) showed that animals with ATN lesions were impaired in the acquisition of the Morris water maze task, and suggests that the ATN plays a role in spatial processing. Although the importance of the ATN as part of the Papez circuit was first recognized many years ago, the informational signal conveyed in this pathway has never been clear. The finding of HD cells in this area and that lesions of this area impair animals on spatial tasks indicate that the ATN and Papez circuit may play a crucial role in navigation. Results showing that postsubicular lesioned animals are also impaired in spatial tasks are consistent with this hypothesis (Taube et al., 1992). Of course the role of the ATN is, however, not limited to spatial information processing, even 


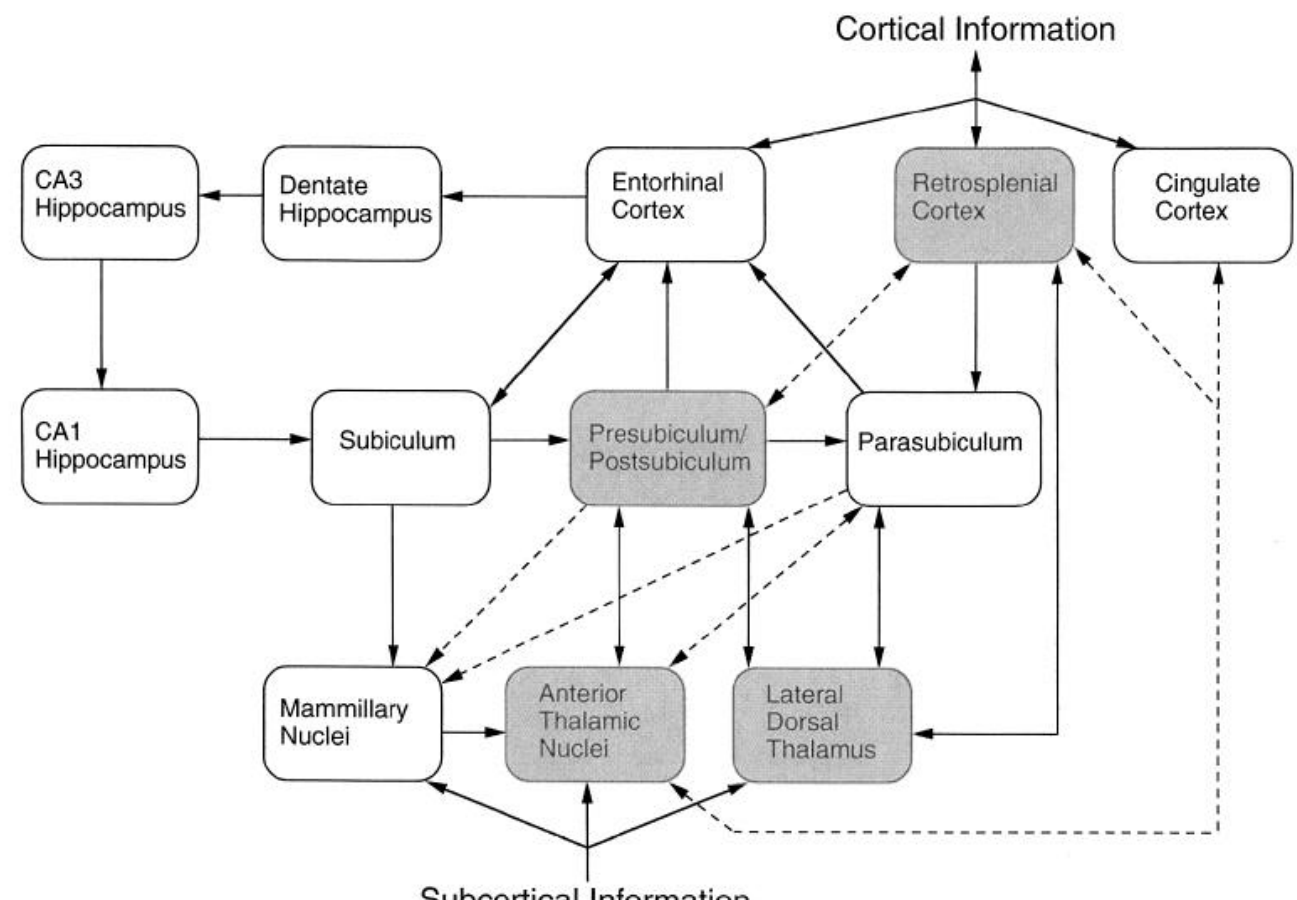

Subcortical Information
Figure 11. Illustration summarizing the principal connections of the postsubiculum and ATN. Areas where HD cells have been reported are indicated by shaded boxes. See Discussion for details. within the $\mathrm{AD}$ portion, since many cells in this area did not discharge as a function of some spatial parameter.

\section{Comparison of ATN and postsubicular HD cells}

The results showed that the discharge properties of ATN HD cells are very similar to the properties of postsubicular HD cells. As with postsubicular cells, ATN cells had preferred directions which were distributed in all head directions. Both types of HD cells contained similar firing rate/head direction functions, peak firing rates, and directional firing ranges. The large variability in peak firing rates among the population of ATN HD cells was also characteristic of the postsubiculum, although the significance of this finding is unclear. The similarity between HD cells in the ATN and postsubiculum also extends to the effects of cue card rotation, where card rotation led to a near-equal shift in the preferred firing direction (Taube et al., 1990b). Taken together, these similarities indicate that the spatial information content encoded by ATN and postsubicular HD cells is comparable. In contrast, the level of place specificity (defined as the ratio between in-field firing to out-of-field firing) varies among different hippocampal areas. For example, place cell specificity appears least in entorhinal cortex and greatest in CA1, with the dentate and CA 3 areas containing intermediate levels (Barnes et al., 1990; Quirk et al., 1992).

The relatively wide range of head directions over which cell firing was elevated $\left(\sim 90^{\circ}\right)$ may at first appear to limit the informational content encoded by a single HD cell. This wide range, however, may not significantly impact the animal's cognitive perception of its head orientation. Studies in the motor cortex have shown that the summed population vector from the population of recorded cells was more accurate in predicting movement of the animal's limb than the firing of individual cells (Georgopoulos et al., 1986). A similar interpretation has recently been proposed for hippocampal place cells with respect to the accurate prediction of an animal's location (Wilson and McNaughton, 1993). Brain areas concerned with the animal's cognitive perception of its directional orientation in an environment may operate in a similar manner. In this scheme, the information content contained in a single HD cell's discharge would not reflect the animal's perceptual head orientation as accurately as the vector-summed activity from the population of HD cells in that brain area. Thus, the wide firing ranges of HD cells would not be a limiting factor in determining the animal's overall perceptual head orientation because the critical variable would be the vector-summed activity of the HD cell population.

One difference noted between the present study and previous recordings of postsubicular HD cells was the higher percentage of HD cells found in the ATN (approximately $60 \%$ in the ATN vs $25 \%$ in the postsubiculum) (Taube et al., 1990a). This finding is also consistent with results showing that simultaneous recordings of multiple HD cells were more frequently encountered in the ATN than in the postsubiculum. Taken together, these findings may reflect the important role the ATN serves in navigation.

The second major difference found between postsubicular and ATN HD cells was that ATN HD cells ceased discharging when the animal was hand-held by the experimenter and rotated passively through the preferred firing direction. Although most postsubicular HD cells reduced their firing rate about $50 \%$ when the animal was hand-held, no postsubicular cells reduced their firing rate to near zero. Interestingly, Foster et al. (1989) reported an absence of firing in hippocampal place cells when the animal was restrained, placed on a wheeled cart, and moved into the cell's place field. They suggested that "hippocampal neuronal activity may reflect the association of movements with their spatial consequences." Similarly, the results in the present study suggest that ATN HD cells require some type of proprioceptive or motor signal for activation. These findings warrant further investigation and will undoubtedly be important in determining the functional roles both place cells and HD cells serve in guiding behavior. Based on the known afferent projections to the $\mathrm{AD}$ 
thalamus (see below) it is unclear whether this motor/proprioceptive information originates in the hippocampal formation, cingulate cortex, or mamillary nuclei. Although most ATN HD cells did not discharge during passive rotation, one ATN cell clearly did discharge under these conditions (Fig. 9C). At present, it is unclear why this cell responded differently. Its possible that during the recording session the animal was not restrained completely and was able to squirm around a little. Alternatively, there may be two distinct types of HD cells in the ATN. Given the difficulty in completely restraining animals under hand-held conditions, more rigorous testing where animals are restrained better is needed to clarify this issue.

\section{Comparison with HD cells recorded in other brain areas}

Previous studies have reported cells showing head directionspecific firing in other brain areas. In a recent study Mizumori et al. (1993) reported the presence of directionally tuned neurons in LDN. With a rat performing a working memory task on an eight arm radial maze the authors found that many LDN cells discharged only when the animal pointed its head in one direction on two arms of the maze which were $180^{\circ}$ opposite one another. Although these characteristics appear similar to postsubicular and ATN HD cells, careful examination of their results show that LDN cells did not discharge on the remaining maze arms when the animal turned around at the end of the arm when it started to proceed back toward the center of the maze. Although, postsubicular and ATN HD cells have not been monitored in a radial maze task, the nature of the head direction signal predicts that they would discharge in the remaining maze arms whenever the animal pointed its head in the preferred direction. Another major difference is that LDN HD cells appeared to require visual input in order to initialize directional firing. In contrast, postsubicular and ATN HD cells did not require visual input for initializing directional firing (Taube et al., 1990b; unpublished observations). In addition, because the description of directionally tuned neurons in LDN did not include firing rate/head direction functions, it remains unclear whether these cells contain similar discharge parameters (e.g., peak firing rate, directional firing range) as ATN and postsubicular HD cells. Until these issues are clarified, it is unclear whether LDN HD cells are similar to ATN or postsubicular HD cells. Similarly, preliminary reports by $\mathrm{Chen}$ and $\mathrm{Mc}-$ Naughton have reported head direction-like cells in the retrosplenial and medial prestriate (Area OcM) cortex (Chen et al., 1990; McNaughton et al., 1991). However, further investigation is needed to determine whether these cells share similar discharge characteristics as postsubicular and ATN HD cells.

In another recent study Wiener (1993) reported a small number of cells in the rat striatum which share similar characteristics and discharge parameters as ATN and postsubicular HD cells. However, striatal HD cells responded differently to rotations of the environment and did not appear to be under control by a salient visual cue. When the behavioral apparatus was rotated $90^{\circ}$, but a dominant visual cue (a light bulb) remained in the same relative position to the outside room, the striatal cells preferred direction rotated with the frame of the apparatus rather than maintaining its relationship to the dominant visual cue. Although Wiener suggested that this difference may be attributed to conflicting inertial cues from vestibular inputs, no experiment was conducted to show that the animal ever used the light bulb for a reference point. Its possible the animal was using some other aspect of the apparatus for a reference point, and rotation of this point during the apparatus rotation would have led to these results. Nonetheless, its clear that striatal cells responded differently to the presence of a salient visual cue than ATN and postsubicular HD cells. In contrast, both ATN and postsubicular HD cells prefer to use the salient visual cue for reference as opposed to directional information from vestibular inputs (Taube et al., 1990b; Goodridge and Taube, 1994).

\section{Processing of the head direction cell signal}

Head direction cells were initially identified in the postsubicular area (dorsal presubiculum) (Ranck, 1985; Taube et al., 1990a). Some investigators recognize the postsubiculum as a fourth distinct area of the subicular complex. The postsubiculum comprises the dorsal portion of the presubiculum. It is not known whether HD cells are found in ventral areas of the presubiculum, although preliminary work by Taube and Amaral has shown that there is little difference in the afferent and efferent projections of the two presubicular areas, suggesting that the ventral presubicular area may also contain HD cells (Taube et al., 1990c). The major inputs into the postsubiculum are from the subiculum, ATN, and LDN thalamus (Niimi, 1978; Sorensen and Shipley, 1979; Thompson and Robertson, 1987a; van Groen and Wyss, 1990a,b, 1992; Shibata, 1993), while the major efferent projections are to the superficial layers of entorhinal cortex, ATN, and LDN thalamus (Swanson and Cowan, 1977; Thompson and Robertson, 1987b; van Groen and Wyss, 1990a,b, 1992). Thus, both the ATN and LDN thalamus contain reciprocal connections with the postsubiculum. In addition to these major connections, the postsubiculum also receives inputs from visual areas 17 and 18, retrosplenial cortex, and anterior cingulate cortex (Vogt and Miller, 1983), and sends projections to the lateral mamillary nucleus (Donovan and Wyss, 1983), areas 17 and 18 (Vogt and Miller, 1983), lateral posterior thalamus (Swanson and Cowan, 1977), and layer I of both retrosplenial and cingulate cortex (Swanson and Cowan, 1977; Vogt and Miller, 1983).

In addition to the postsubiculum, the ATN receive inputs from the mamillary nuclei, cingulate cortex, and retrosplenial cortex. In turn, the ATN send reciprocal projections to anterior cingulate cortex and retrosplenial granular cortex. Within the ATN, there is a high degree of specificity for both the afferent and efferent projections. For example, the medial mamillary nucleus projects to all three ATN, but the lateral mamillary nucleus projects only to AD (Guillery, 1957; Cruce, 1975). Afferents from the cingulate and retrosplenial cortices terminate in AV and AM (Domesick, 1969; Beckstead, 1979). In contrast, the $\Lambda V$ and $\Lambda D$ both project to the retrosplenial granular cortex whereas the AM projects only to the anterior cingulate (Domesick, 1972; Beckstead, 1976). The ATN projections to the postsubiculum arise mostly from AV and AD (Wyss et al., 1979; Shibata, 1993). The major connections of the postsubiculum and ATN are summarized in Figure 11. Structures where HD cells have been reported are indicated by shaded boxes.

Previous recording studies which monitored single-unit activity in the subiculum of freely moving animals have only reported location-specific firing (Barnes et al., 1990; Mizumori et al., 1992; Sharp and Green, 1994). Many subicular place cells, however, showed a secondary directional correlate when the animal was recorded on the eight arm radial maze. That is, subicular cells were found which discharged in one arm of the maze, but only when the animal was pointing its head in one direction within that arm. This secondary directional correlate 
is usually observed in hippocampal place cells when recording on the radial maze (McNaughton et al., 1983; Muller et al., 1994). Despite these secondary directional correlates, none of the subicular studies reported the type of head direction correlate observed in the ATN or postsubiculum. Consistent with these recording studies are anatomical findings showing an absence of an ATN projection to the subiculum (Wyss et al., 1979) and only sparse, if any, projections from the subiculum to the ATN (Meibach and Seigel, 1977; Donovan and Wyss, 1983; Witter et al., 1990).

The finding of HD cells in the ATN indicates the potential importance this structure may play in processing the directional signal. However, because there are reciprocal connections between the postsubiculum and the ATN, the origin of the HD cell signal remains unclear. Lesion studies which selectively disrupt one area while simultaneously recording from the other area may determine the direction in which the head direction signal is flowing. To address this issue, Goodridge and Taube (1993a) have recently shown in a preliminary report that electrolytic lesions of the ATN led to the absence of finding HD cells when subsequently recording from the postsubiculum. This finding suggests that the ATN projection to the postsubiculum is critical for the establishment of postsubicular HD cell discharge. Finally, the importance of the mamillary nuclei to the ATN head direction signal is not known. Although the ATN, including $\mathrm{AD}$, receive a major projection from the mamillary nuclei, there have been no studies reporting the spatial correlates of mamillary cells. Furthermore, given the dense projection of postsubicular fibers to the lateral mamillary nuclei, monitoring of cells in this region is warranted.

Other brain areas may also be critical for the establishment of the HD cell signal. As discussed above, Mizumori and colleagues have reported directionally tuned neurons in the LDN. Although it is unclear whether LDN neurons have similar discharge properties as postsubicular and ATN HD cells, the finding of a directional signal in this brain area suggests that the LDN may also be a source for the formation of the $\overline{H D}$ cell signal. However, as with the ATN, the LDN also contains reciprocal connections with the postsubiculum and further experiments are necessary to determine the direction of flow of this spatial signal. The finding of HD cells in the striatum (Wiener, 1993) is probably due to directional information projected from the retrosplenial cortex to the striatum because there is an absence of striatal projections to the ATN and postsubiculum.

Chen and colleagues have also reported head directional correlates for cells in the retrosplenial and OcM cortices (Chen et al., 1990; McNaughton et al., 1991). However, it is more parsimonious to attribute the retrosplenial head direction signal to efferent projections from either the postsubiculum, AD, or LDN than as the origin of the head direction signal because (1) the $\mathrm{AD}$, where most ATN head direction were localized, projects to the retrosplenial cortex, but does not receive reciprocal projections (only AV contains reciprocal connections) (Domesick, 1969,1972 ; Beckstead, 1976, 1979) and (2) the LDN projects directly to the retrosplenial cortex (Thompson and Robertson, 1987; van Groen and Wyss, 1992). Furthermore, although there is a direct projection from retrosplenial cortex to postsubiculum, the reciprocal connection of postsubiculum to retrosplenial cortex is the more dense projection (Taube et al., 1990c). In contrast, the OcM area is considered part of the rat visual cortex and does send projections to the postsubiculum (Vogt and Miller, 1983). Therefore, its possible for the OcM projections to be a pathway where visual information regarding directional orientation is conveyed to the postsubiculum. Alternatively, visual information may access the subicular cortex through the ATN directly, since studies have shown that the retina has access to neural circuits within the ATN (Conrad and Stumpf, 1975; Itaya et al., 1981). The findings from the cue card rotation experiments showing that selective visual cues can exert control over ATN directional firing is consistent with these anatomical studies.

In conclusion, the present study demonstrates the presence of HD cells in the ATN and indicates that they have similar discharge properties as postsubicular HD cells. The preferred firing direction of ATN direction cells can be controlled by a salient visual cue, although locomotion by the animal may be necessary to elicit cell firing. Finally, because there are reciprocal connections between the postsubiculum and ATN, future studies will need to determine the origin of this spatial signal.

\section{References}

Barnes CA, McNaughton BL, Mizumori SJY, Leonard BW, Lin L-H (1990) Comparison of spatial and temporal characteristics of neuronal activity in sequential stages of hippocampal processing. Prog Brain Res 83:287-300.

Batschelet E (1981) Circular statistics in biology. New York: Academic.

Beckstead RM (1976) Convergent thalamic and mesencephalic projections to the anterior medial cortex in the rat. J Comp Neurol 166 : 403-416.

Beckstead RM (1979) An autoradiographic examination of corticocortical and subcortical projections of the mediodorsal-projection (prefrontal) cortex in the rat. J Comp Neurol 184:43-62.

Chen LL, McNaughton BL, Barnes CA, Ortiz ER (1990) Head-directional and behavioral correlates of posterior cingulate and medial prestriate cortex neurons in freely-moving rats. Soc Neurosci Abstr 16:441.

Conrad CD, Stumpf WE (1975) Direct visual input to the limbic system: crossed retinal projections to the nucleus anterodorsalis thalami in the tree shrew. Exp Brain Res 23:141-149.

Corkin S (1984) Lasting consequences of bilateral medial temporal lobectomy: clinical course and experimental findings in H.M. Semin Neurol 4:249-259.

Cruce JAF (1975) An autoradiographic study of the projections of the mammillothalamic tract in the rat. Brain Res 85:211-219.

De Leon MJ, Potegal M, Gurland B (1984) Wandering and parietal signs in senile dementia of Alzheimer's type. Neuropsychobiology 11 : 155-157.

Domesick VB (1969) Projections from the cingulate cortex in the rat. Brain Res 12:296-320.

Domesick VB (1972) Thalamic relationships of the medial cortex in the rat. Brain Behav Evol 6:457-483.

Donovan MK, Wyss JM (1983) Evidence for some collateralization between cortical and diencephalic efferent axons of the rat subicular cortex. Brain Res 259:181-192.

Foster K, Orona E, Lambert RW, Gabriel M (1980) Early and late acquisition of discriminative neuronal activity during differential conditioning in rabbits: specificity within the laminae of cingulate cortex and the anteroventral thalamus. J Comp Physiol Psychol 94:10691086.

Foster T, Castro CA, McNaughton BL (1989) Spatial selectivity of rat hippocampal neurons: dependence on preparedness for movement. Science 244:1580-1582.

Gabriel M, Miller J, Saltwick SE (1977) Unit activity in cingulate cortex and anteroventral thalamus of the rabbit during differential conditioning and reversal. J Comp Physiol Psychol 91:423-433.

Gabriel M, Sparenborg SP, Stolar N (1987) Hippocampal control of cingulate cortical and anterior thalamic information processing during learning in rabbits. Exp Brain Res 67:131-152.

Georgopoulos AP, Schwartz AB, Kettner RE (1986) Neuronal population coding of movement direction. Science 233:1416-1419.

Goodridge JP, Taube JS (1993) Lesions of the rat anterior thalamic nucleus disrupts head direction cell firing in the postsubiculum. Soc Neurosci Abstr 19:796. 
Goodridge JP, Taube JS (1994) Preferential use of the landmark navigational system by head direction cells. Beh Neurosci, in press.

Guillery RW (1957) Degeneration in the hypothalamic connexions of the albino rat. J Anat 93:403-419.

Itaya SK, Van Hoesen GW, Jenq CB (1981) Direct retinal input to the limbic system of the rat. Brain Res 226:33-42.

Jung MW, McNaughton BL (1993) Spatial selectivity of unit activity in the hippocampal granule layer. Hippocampus 3:165-182.

Kubie JL (1984) A drivable bundle of microwires for collecting singleunit data from freely moving rats. Physiol Behav 32:115-118.

McNaughton BL, Barnes CA, O'Keefe J (1983) The contributions of position, direction, and velocity to single unit activity in the hippocampus of freely-moving rats. Exp Brain Res 52:41-49.

McNaughton BL, Chen LL, Markus EJ (1991) "Dead reckoning," landmark learning, and the sense of direction: a neurophysiological and computational hypothesis. J Cognit Neurosci 3:190-202.

Meibach RC, Siegel A (1977) Thalamic projections of the hippocampal formation: evidence for an alternate pathway involving the internal capsule. Brain Res 134:1-12.

Mizumori SJY, Williams JD (1993) Directionally selective mnemonic properties of neurons in the lateral dorsal nucleus of the thalamus of rats. J Neurosci 13:4015-4028.

Mizumori SJY, Ward KE, Lavoie AM (1992) Medial septal modulation of entorhinal single unit activity in anesthetized and freely moving rats. Brain Res 570:188-197.

Morris RGM, Garrud P, Rawlins JNP, O'Keefe J (1982) Place navigation impaired in rats with hippocampal lesions. Nature 297:681683.

Muller RU, Kubie JL (1987) The effects of changes in the environment on the spatial firing of hippocampal complex-spike cells. J Neurosci 7:1951-1968.

Muller RU, Kubie JL, Ranck JB Jr (1987) Spatial firing patterns of hippocampal complex-spike cells in a fixed environment. J Neurosci 7:1935-1950.

Muller RU, Bostock EM, Taube JS, Kubie JL (1994) On the directional firing properties of hippocampal place cells. J Neurosci, in press.

Niimi M (1978) Cortical projections of the anterior thalamic nuclei in the cat. Exp Brain Res 31:403-416.

O'Keefe J (1976) Place units in the hippocampus of the freely moving rat. Exp Neurol 51:78-109.

O'Keefe J, Conway DH (1978) Hippocampal place units in the freely moving rat: why they fire where they fire. Exp Brain Res 31:573-590.

O'Keefe J, Nadel L. (1978) The hippocampus as a cognitive map. Oxford: Clarendon.

O'Keefe J, Speakman A (1987) Single unit activity in the rat hippocampus during a spatial memory task. Exp Brain Res 68:1-27.

Olton DS, Becker JT, Handelmann GE (1979) Hippocampus, space, and memory. Behav Brain Sci 2:313-365.

Paxinos G, Watson C (1986) The rat brain in stereotaxic coordinates. New York: Academic.

Quirk GJ, Muller RU, Kubie JL, Ranck JB Jr (1992) The positional firing properties of medial entorhinal neurons: description and comparison with hippocampal place cells. J Neurosci 12:1945-1963.

Ranck JB Jr (1973) Studies on single neurons in dorsal hippocampal formation and septum in unrestrained rats. Part I. Behavioral correlates and firing repertoires. Exp Neurol 41:461-535.

Ranck JB Jr (1985) Head direction cells in the deep cell layer of dorsal presubiculum in freely moving rats. In: Electrical activity of the archicortex (Buzsaki G, Vanderwolf $\mathrm{CH}$, eds), pp 217-220. Budapest: Hungarian Academy of Sciences.

Sharp PE, Green C (1994) Spatial correlates of firing patterns of single cells in the subiculum of the freely moving rat. J Neurosci 14:23392356.

Shibata H (1993) Direct projections from the anterior thalamic nuclei to the retrohippocampal region in the rat. J Comp Neurol 337:431445.

Sorensen KE, Shipley MT (1979) Projections from the subiculum to the decp layers of the ipsilateral presubicular and entorhinal cortices in the guinea pig. J Comp Neurol 188:313-334.

Sparenborg S, Gabriel M (1990) Neuronal encoding of conditional stimulus duration in the cingulate cortex and the limbic thalamus of rabbits. Behav Neurosci 104:919-933.

Sutherland RJ, Rodriguez AJ (1989) The role of the fornix/fimbria and some related subcortical structures in place learning and memory. Behav Brain Res 32:265-277.

Swanson LW, Cowan WM (1977) An autoradiographic study of the organization of the efferent connections of the hippocampal formation in the rat. J Comp Neurol 172:49-84.

Taube JS (1992) Quantitative analysis of head-direction cells recorded in the rat anterior thalamus. Soc Neurosci Abstr 18:708.

Taube JS, Muller RU, Ranck JB Jr (1990a) Head-direction cells recorded from the postsubiculum in freely moving rats. I. Description and quantitative analysis. J Neurosci 10:420-435.

Taube JS, Muller RU, Ranck JB Jr (1990b) Head-direction cells recorded from the postsubiculum in freely moving rats. II. Effects of environmental manipulations. J Neurosci 10:436-447.

Taube JS, Scalia F, Amaral DG (1990c) Connectivity of the dorsal and ventral presubiculum of the rat. Soc Neurosci Abstr 16:122.

Taube JS, Kesslak JP, Cotman CW (1992) Lesions of the rat postsubiculum impair performance on spatial tasks. Behav Neural Biol 57:131-143.

Thompson LT, Best PJ (1990) Long-term stability of the place-field activity of single units recorded from the dorsal hippocampus of freely moving rats. Brain Res 509:299-308.

Thompson SM, Robertson RT (1987a) Organization of subcortical pathways for sensory projections to the limbic cortex. I. Subcortical projections to the medial limbic cortex in the rat. J Comp Neurol 265:175-188.

Thompson SM, Robertson RT (1987b) Organization of subcortical pathways for sensory projections to the limbic cortex. II. Afferent projections to the thalamic lateral dorsal nucleus in the rat. J Comp Neurol 265:189-202.

Vanderwolf $\mathrm{CH}$ (1969) Hippocampal electrical activity and voluntary movement in the rat. Electroencephalogr Clin Neurophysiol 26:407418.

van Groen T, Wyss JM (1990a) The connections of presubiculum and parasubiculum in the rat. Brain Res 518:227-243.

van Groen T, Wyss JM (1990b) The postsubicular cortex in the rat: characterization of the fourth region of the subicular cortex and its connections. Brain Res 529:165-177.

van Groen T, Wyss JM (1992) Projections from the laterodorsal nucleus of the thalamus to the limbic and visual cortices in the rat. $J$ Comp Neurol 324:427-448.

Vogt BA, Miller MW (1983) Cortical connections between rat cingulate cortex and visual, motor, and postsubicular cortices. J Comp Neurol 216:192-210.

Wiener SI (1993) Spatial and behavioral correlates of striatal neurons in rats performing a self-initiated navigation task. J Neurosci 13: 3802-3817.

Wilson MA, McNaughton BL (1993) Dynamics of the hippocampal ensemble code for space. Science 261:1055-1058.

Witter MP, Ostendorf RH, Groenewegen HJ (1990) Heterogeneity in the dorsal subiculum of the rat. Distinct neuronal zones project to different cortical and subcortical targets. Eur J Neurosci 2:718-725.

Wyss JM, Swanson LW, Cowan WM (1979) A study of subcortical afferents to the hippocampal formation in the rat. Neuroscience 4:463476. 